\title{
Porous $\mathrm{TaC}_{\mathrm{x}}$ ISOL target materials from mould-casted $\mathrm{Ta}_{4} \mathrm{AIC}_{3}$
}

Matteo Griseri ${ }^{\star, a, b}$, Jonas Biggemann ${ }^{* *, c}$, João Pedro Ramos ${ }^{a}$, Guichuan Li ${ }^{\mathrm{b}}$, Ot Dams ${ }^{\mathrm{a}}$, Lucia Popescu $^{a}$, Jozef Vleugels ${ }^{b}$, Tobias Fey ${ }^{c, d}$, and Konstantina Lambrinou ${ }^{a, e}$

a SCK CEN, Boeretang 200, 2400 Mol, Belgium

${ }^{\mathrm{b}} \mathrm{KU}$ Leuven, Department of Materials Engineering, Kasteelpark Arenberg 44, 3001 Leuven, Belgium

'Department of Materials Science and Engineering, Institute of Glass and Ceramics, FriedrichAlexander-Universität Erlangen-Nürnberg, Martensstr. 5, 91058 Erlangen, Germany

d Frontier Research Institute for Materials Science, Nagoya Institute of Technology, Gokisocho, Showa-ku, Nagoya 466-8555, Japan

e School of Computing and Engineering, University of Huddersfield, Huddersfield HD1 3DH, UK

*Corresponding author: matteo.griseri@kuleuven.be

** Second corresponding author: jonas.biggemann@fau.de

\section{Abstract}

Mould casting and sacrificial templating techniques, common in bioceramic technology, were employed to process porous $\mathrm{TaC}_{\mathrm{x}}$ ultra-high temperature ceramics intended as novel target materials for isotope separation on-line (ISOL) facilities, aiming primarily at the production of medical radioisotopes. A feedstock of $\mathrm{Ta}_{4} \mathrm{AIC}_{3} \mathrm{MAX}$ phase powder, polyamide spheres and wax was used to obtain different porous $\mathrm{TaC}_{\mathrm{x}}$ grades with bimodal pore size distributions. The 'green' bodies underwent de-binding and vacuum annealing to decompose the MAX phase, whereas a reference material was also produced from commercial TaC powders. The thermal stability of the porous $\mathrm{TaC}_{\mathrm{x}}$ ceramics was assessed at ISOL-relevant conditions by heating in high vacuum up to $2200^{\circ} \mathrm{C}$. The MAX phase-derived $\mathrm{TaC}_{x}$ porous ceramics evolved from biphasic $\mathrm{TaC}_{x} / \alpha-\mathrm{Ta}_{2} \mathrm{C}$ to single-phase $\mathrm{TaC}_{\mathrm{x}}$ at higher temperatures, due to carbon incorporation. The porous $\mathrm{TaC}_{\mathrm{x}}$ microstructure was stable at $2200^{\circ} \mathrm{C}$ with a specific surface area stabilizing at $\sim 0.25 \mathrm{~m}^{2} / \mathrm{g}$ and thermal conductivity of $1-4 \mathrm{~W} / \mathrm{m} \cdot \mathrm{K}$.

Keywords: Mould casting; $\mathrm{Ta}_{4} \mathrm{AIC}_{3} \mathrm{MAX}$ phase; porous ultrahigh temperature ceramics; ISOL target materials; $\mathrm{TaC}_{\mathrm{x}}$ 


\section{Introduction}

In Isotope Separation On-Line (ISOL) facilities, an accelerated proton beam and a target are used to produce short-lived (exotic) radionuclides in the form of radioactive ion beams (RIBs) for a variety of applications, including nuclear medicine research $[1,2]$. A characteristic of the ISOL technique is the continuous evaporation and separation of the produced radionuclides from a target material with a high specific surface area (SSA), often a solid with an open porous structure up to $\sim 90$ vol\% [3-6]. The target is irradiated and kept at high temperature (up to $2200^{\circ} \mathrm{C}$ ) in order to enhance the diffusion and effusion of the reaction products within the material and the rate at which they reach the surface and evaporate. In principle, the higher the operation temperature, the higher the overall isotope release efficiency of the target material. However, the temperature- and irradiation-induced sintering can reduce the pore interconnectivity and SSA during target operation. This phenomenon negatively affects the release performance over time and depends largely on the transport properties of the specific element within the material. Therefore, an important aim of target material development is to ensure the high-temperature material microstructural stability. For example, standard $27 \%$ TD $\left(\% \mathrm{TD}=\right.$ percent of theoretical density) uranium carbide-carbon $\left(\mathrm{UC}_{2-\mathrm{x}}+\mathrm{xC}\right)$ targets used at the ISOLDE facility in CERN would decrease their release of ${ }^{30} \mathrm{Na}$ by one order of magnitude after $\sim 100 \mathrm{~h}$ of operation at $2100^{\circ} \mathrm{C}$, but this is entirely avoided by switching to nano- $U C_{\mathrm{x}}$ with $10.6 \% \mathrm{TD}$, due to the improved target microstructural stability [7].

Because of their different (target-specific) production cross-sections, uranium-based targets provide wide access to the nuclide chart, whereas tantalum-based targets are better suited for the production of spallation, fragmentation and fission products in the neutron-deficient regions of the chart $[7,8]$. With proton energies that exceed hundreds of $\mathrm{MeV}$, tantalum (Ta) possesses a large cross-section for the production of radiolanthanides, several isotopes of which have applications in nuclear medicine. Ta-based target materials are proposed for the production of ${ }^{149} \mathrm{~Tb}$ (half-life $\mathrm{T}_{1 / 2}=4.118 \mathrm{~h}$ ) for combined PET (Positron Emission Tomography)/a-therapy in cancer radio-theranostics [9,10], along with other longer-lived terbium $(\mathrm{Tb})$ isotopes, i.e., ${ }^{152} \mathrm{~Tb}$ $\left(\mathrm{T}_{1 / 2}=17.5 \mathrm{~h}\right),{ }^{155} \mathrm{~Tb}\left(\mathrm{~T}_{1 / 2}=5.32 \mathrm{~d}\right)$ and ${ }^{156} \mathrm{~Tb}\left(\mathrm{~T}_{1 / 2}=5.35 \mathrm{~d}\right)$ for PET, computed tomography, and SPECT (Single-Photon Emission Computed Tomography) [2].

While refractory carbides have already been introduced in the ISOL community for actinidebased targets, such as $\mathrm{ThC}_{\mathrm{x}}$ and $\mathrm{UC}_{\mathrm{x}}[7,8,11,12]$, and recently for lighter targets, such as nanometric $\mathrm{TiC}[13]$ and $\mathrm{SiC}[14,15]$, Ta-based targets have so far only been used in the form of metallic Ta thin foils (melting point $\approx 3016^{\circ} \mathrm{C}$ ). Therefore, the introduction of $\mathrm{TaC}_{\mathrm{x}}$ (melting point $\approx 3880^{\circ} \mathrm{C}$, for $\mathrm{x}=1$ ) as target material is being investigated in order to increase the refractoriness and the operational time of the target under intense primary beams. During ISOL operation, the intensity of the primary beam is generally a direct multiplier for the final number of produced radioisotopes. Certain running projects, such as ISOL@MYRRHA at SCK CEN, aim at operating targets using beam intensities up to $500 \mu \mathrm{A}$ [16-18]. Operating $\mathrm{TaC}_{\mathrm{x}}$-based targets in the $2000-2200^{\circ} \mathrm{C}$ temperature range can - in combination with a high-intensity proton beam and an appropriate target design - provide the conditions to produce the mentioned medical isotopes in the 100-1000 MBq order of magnitude of activity (1 Becquerel = 1 decay/s), which is considered sufficient for preclinical studies [9].

The present study proposes a processing route based on the mould casting of a master feedstock made of wax, a pore former, and $\mathrm{Ta}_{4} \mathrm{AIC}_{3} \mathrm{MAX}$ phase precursor powder. The combination of mould casting with sacrificial templating is a processing technology that has been reported for different material systems as capable of producing complex 3D geometries 
with precisely tailored material microstructures [19-24]. This near-net shape manufacturing technology allows the control of the total porosity and pore size distribution of the produced materials by changing the amount, shape and size of the utilized pore formers. Various potential applications, such as bone and/or dental implants, are currently implementing this manufacturing technology, thereby producing precisely tailored porous ceramics for specific targeted applications $[25,26]$. As opposed to commercially available TaC powders, in-house produced $\mathrm{Ta}_{4} \mathrm{AlC}_{3}$ MAX phase powder was used as ceramic component of the feedstock. Despite the lengthier process, this route brings some advantages due to the ease with which it can be milled from a large sintered body to a customised particle size distribution, and due to its lower carbon $(C)$ stoichiometry. The latter property could be beneficial for the extraction of species that bind with $C$ in the host lattice, delaying their release during ISOL target operation. This MAX phase decomposes into $\mathrm{TaC}_{0.75}$ and gaseous aluminium (Al) above $1200^{\circ} \mathrm{C}$ in vacuum, as described in previous work [27]. Moreover, the $\mathrm{C}$ content of $\mathrm{TaC}_{\mathrm{x}}$ correlates to the melting point, which peaks at $\mathrm{x} \approx 0.9$, according to the Ta-C equilibrium phase diagram [28], resulting in a possibly higher resistance to sintering as well as loss of SSA and pore interconnectivity during target operation at high temperatures. Three different levels of additional porosity $(5 \%, 10 \%$ and $15 \%)$ were introduced by adding increasingly larger amounts of spherical pore formers $(\varnothing \sim 70 \mu \mathrm{m})$. The aim was to obtain an additional distribution of larger pores in the porous $\mathrm{TaC}_{\mathrm{x}}$ 'matrix' of 50\%TD targeted density, so as to produce porous ceramics with a bimodal pore size distribution. The size of the pore formers was roughly an order of magnitude larger than the starting $\mathrm{TaC}_{\mathrm{x}}$ powder particle size.

In order to study the microstructural stability of perspective $\mathrm{TaC}_{\mathrm{x}}$-based porous target materials produced with this process, various annealing heat treatments were conducted in the 1500$1850^{\circ} \mathrm{C}$ range in a high-vacuum furnace, as well as at $2200^{\circ} \mathrm{C}$ in a specifically designed setup. Even though these heat treatments lasted only up to $12 \mathrm{~h}$, which is shorter than the proposed operation time $(\sim 600 \mathrm{~h})$ for such targets, they are considered sufficiently long to assess the initial effects of high-temperature annealing on porous target stability, as also studied previously on nano- $\mathrm{TiC}_{\mathrm{x}}$ materials annealed for $10 \mathrm{~h}$ [5]. The same processing routes and heat treatments were reproduced using commercial pre-milled TaC powders, and the results were compared to those obtained using the $\mathrm{Ta}_{4} \mathrm{AlC}_{3} \mathrm{MAX}$ phase precursor. In summary, the present study aimed at: (a) developing a processing route for the production of $\mathrm{TaC}_{\mathrm{x}}$ target materials with $35-50 \%$ TD, corresponding to $65-50$ vol\% of open macroporosity that had to be introduced into the material without jeopardising its integrity, and (b) assessing the effect of the hightemperature residence of the produced target materials on their microstructures and porosities (i.e., under conditions relevant for the operation of an ISOL target).

\section{Experimental procedure}

\subsection{Processing}

The $\mathrm{Ta}_{4} \mathrm{AlC}_{3} \mathrm{MAX}$ phase material was obtained in a highly pure bulk form by reactive hot pressing of elemental powder mixtures at $1500^{\circ} \mathrm{C}$ for $30 \mathrm{~min}$, following the process reported elsewhere [27]. The dense $\mathrm{Ta}_{4} \mathrm{AlC}_{3}$ discs were crushed in a ring mill (RS200, Retsch, Germany) at $1000 \mathrm{rpm}$ in repeated cycles of $1 \mathrm{~min}$, after which the powder was sieved through a $25 \mu \mathrm{m}$-mesh sieve (Retsch, Germany). Particle size analysis (Beckman Coulter LS 13 320, USA) was conducted on ethanol suspensions. The mean particle size of the $\mathrm{Ta}_{4} \mathrm{AlC}_{3}$ powder was measured to be $(4.2 \pm 3.9) \mu \mathrm{m}$, with $(\mathrm{dn} 10, \mathrm{dn} 50, \mathrm{dn} 90)=(0.6,3.0,9.4) \mu \mathrm{m}$. 
As the starting powder particles might be slightly oxidized, they could carry hydrophilic surface groups that are incompatible with a hydrophobic paraffin binder, causing agglomeration and inhomogeneous dispersion. This was avoided by hydrophobization of the $\mathrm{Ta}_{4} \mathrm{AlC}_{3}$ powder by means of electrosteric stabilization using stearic acid as surfactant, a technique often used to obtain low-viscosity ceramic slurries [23,24,29,30]. $\mathrm{Ta}_{4} \mathrm{AlC}_{3}$ and $0.15 \mathrm{wt} \%$ stearic acid (Grade I, $\geq 98.5 \%$, Sigma-Aldrich, USA) were mixed on a low-energy rotatory mixer in $n$-hexane with $20 \mathrm{wt} \% \mathrm{Ta}_{4} \mathrm{AlC}_{3}$ powder for $12 \mathrm{~h}$.

A master feedstock batch consisting of 50 vol\% hydrophobic $\mathrm{Ta}_{4} \mathrm{AlC}_{3}$ powder, 44.9 vol\% paraffin (Sigma-Aldrich, Germany), and 5.1 vol\% carnauba wax (Sigma-Aldrich, Germany) was prepared and homogenized by mechanical stirring in a thermal bath at $120^{\circ} \mathrm{C}$ for $12 \mathrm{~h}$. Around $50 \%$ of the 'green' body's volume was occupied by the binder, in order to produce a debound matrix of powder particles with interconnected porosity, which translated directly into open porosity after the material's densification by sintering. From this master feedstock batch, three additional batches were prepared with the addition of pore-forming polyamide (PA) spheres with a mean particle size of $(70 \pm 32) \mu \mathrm{m}$ and $(\mathrm{dn} 10, \mathrm{dn} 50, \mathrm{dn} 90)=(34.5,67.1,110.9) \mu \mathrm{m}$ (Duraform 3D Systems, Canada). The PA spheres were added during stirring, while the feedstock was kept at $120^{\circ} \mathrm{C}$. The same process was repeated using a commercial TaC powder (Ningxia, China) with a mean particle size of $(3.2 \pm 1.9) \mu \mathrm{m}$ and $(\mathrm{dn} 10, \mathrm{dn} 50, \mathrm{dn} 90)=$ $(1.8,2.6,4.8) \mu \mathrm{m}$. The commercial TaC powder was used as reference to compare with the $\mathrm{Ta}_{4} \mathrm{AIC}_{3} \mathrm{MAX}$ phase powder in terms of microstructural/thermal stability and overall suitability of the produced porous ceramics for the ISOL target application. Fig. 1a shows the particle size distributions of both ceramic powders and spherical PA pore-formers. The milled MAX phase powder had a broader particle size distribution when compared to the commercial TaC powder, as well as a larger tail of smaller sizes characteristic of a lab-milled powder.

The eight produced material grades are summarized in Table 1, which introduces a nomenclature for each grade. The grades produced from $\mathrm{Ta}_{4} \mathrm{AlC}_{3}(\mathrm{~T})$ powders with or without PA pore-forming spheres (P) are referred to as T50, TP45, TP40 and TP35, where the number refers to the targeted percent of theoretical density (\%TD). Similarly, the grades produced from commercial TaC (TC) powders, henceforth described as 'reference grades', are referred to as TC50, TCP45, TCP40 and TCP35.

\section{Table 1}

Compositions produced from $\mathrm{Ta}_{4} \mathrm{AlC}_{3}(\mathrm{~T})$ and commercial $\mathrm{TaC}$ (TC) ceramic powders, some of them mixed with PA polymer $(P)$ spheres.

\begin{tabular}{ccc}
\hline Grade & Targeted \%TD & vol\% of PA spheres \\
\hline T50, TC50 & 50 & 0 \\
\hline TP45, TCP45 & 45 & 10 \\
\hline TP40, TCP40 & 40 & 20 \\
\hline TP35, TCP35 & 35 & 30 \\
\hline
\end{tabular}



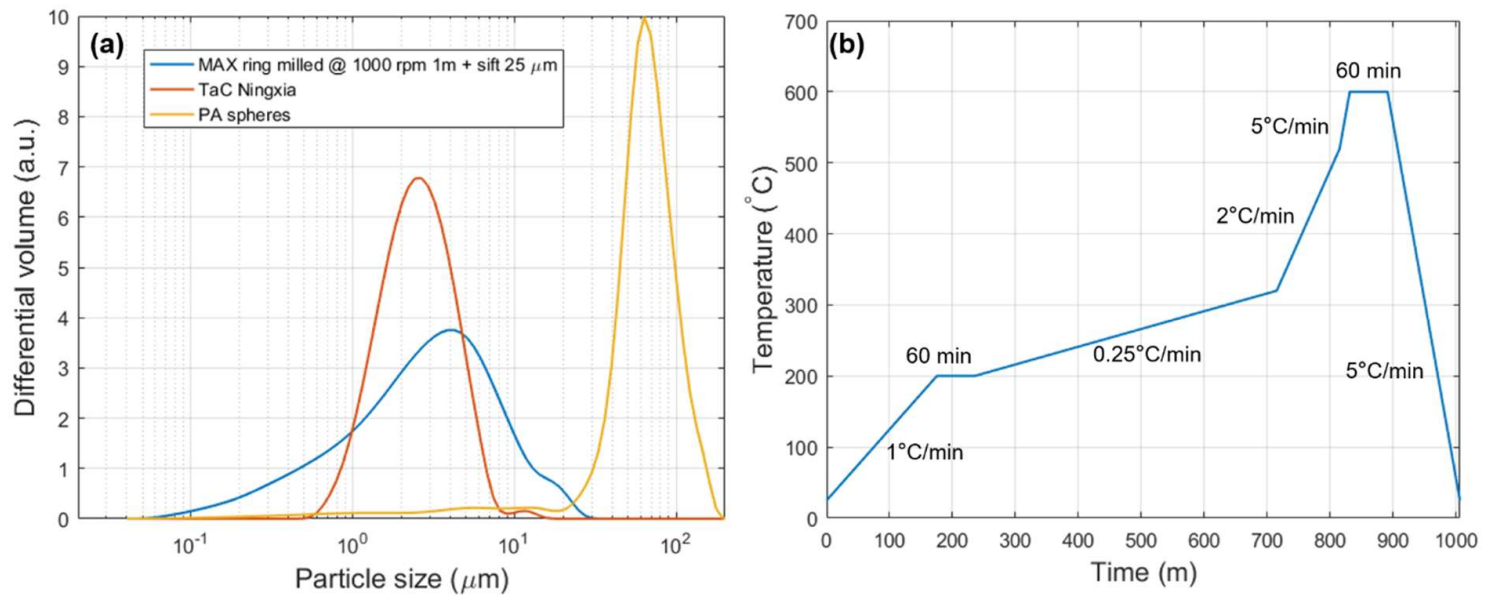

Fig. 1. (a) Particle size analysis of $\mathrm{Ta}_{4} \mathrm{AIC} \mathrm{C}_{3}$ powder, commercial $\mathrm{TaC}$ powder, and PA spheres. (b) Heating profiles for wax debinding and pore-formers' pyrolysis up to $600^{\circ} \mathrm{C}$.

The feedstock material was poured in disc-shaped silicone moulds $(\varnothing 15 \mathrm{~mm})$, inside a furnace heated at $120^{\circ} \mathrm{C}$. In order to evaporate/debind the wax and pyrolyse the pore-formers to convert the 'green' discs into 'brown' bodies, the shaped $(\varnothing 15 \mathrm{~mm}$, thickness $\approx 2 \mathrm{~mm}$ ) 'green' discs were positioned on a porous alumina substrate (KVS1800, Rath), in a horizontal tube furnace ( $\mathrm{SiC}$ heating element, Hermann Moritz). Pyrolysis was carried out up to $600^{\circ} \mathrm{C}$ in an argon (Ar) atmosphere (gas flow rate: $30 \mathrm{l} / \mathrm{min}$ ). In order to avoid bubble formation in the lowtemperature segments of the processing profile where the wax evaporates, slow heating rates of $1^{\circ} \mathrm{C} / \mathrm{min}$ below $200^{\circ} \mathrm{C}$ and $0.25^{\circ} \mathrm{C} / \mathrm{min}$ until $320^{\circ} \mathrm{C}$ were used. Faster heating was used in the segments where PA pyrolysis occurs, i.e., $2^{\circ} \mathrm{C} / \mathrm{min}$ until $520^{\circ} \mathrm{C}$ and $5^{\circ} \mathrm{C} / \mathrm{min}$ until $600^{\circ} \mathrm{C}$. This cycle, indicated in Fig. 1b, was completed with a dwell of $60 \mathrm{~min}$, followed by cooling to room temperature $(\mathrm{RT})$ at $5^{\circ} \mathrm{C} / \mathrm{min}$. The 'brown' bodies based on commercial TaC powder exhibited poorer mechanical integrity, often needing to be discarded due to cracks and mechanical damage. The pyrolysed discs were transferred to a vacuum $\left(10^{-5} \mathrm{mbar}\right)$, resistively heated furnace with a tungsten $(\mathrm{W})$ heating element. This furnace will be further referred to as "W furnace". The discs were heated at $20^{\circ} \mathrm{C} / \mathrm{min}$ to $1500^{\circ} \mathrm{C}$ for $4 \mathrm{~h}$, in order to decompose the $\mathrm{Ta}_{4} \mathrm{AlC}_{3} \mathrm{MAX}$ phase into $\mathrm{TaC}_{\mathrm{x}}$ and consolidate (i.e., pre-sinter) the resulting ceramic. This temperature/dwell time combination ensures a nearly complete decomposition of the $\mathrm{Ta}_{4} \mathrm{AlC}_{3}$ MAX phase into the corresponding $\mathrm{TaC}_{\mathrm{x}}$ binary carbides. The consolidation of the commercial TaC powder grades involved direct annealing at higher temperatures, i.e., for $2 \mathrm{~h}$ at $1850^{\circ} \mathrm{C}$ in the same $W$ furnace (see also section 2.2).

\subsection{Heat treatments in vacuum}

In order to test the high-temperature stability of the porous ceramics at temperatures near to those of an ISOL target in operation, the $\mathrm{Ta}_{4} \mathrm{AlC}_{3} \mathrm{MAX}$ phase-derived grades obtained after consolidation underwent further annealing heat treatments in the $\mathrm{W}$ furnace, but at higher temperatures, i.e., at $1600^{\circ} \mathrm{C}$ and $1850^{\circ} \mathrm{C}$, for a dwell time of $2 \mathrm{~h}$, and at a heating rate of $20^{\circ} \mathrm{C} / \mathrm{min}$. Additional heat treatments were performed at temperatures $\sim 2200^{\circ} \mathrm{C}$ for $2 \mathrm{~h}$ and 12 $\mathrm{h}$ (targeted heating rate: $20^{\circ} \mathrm{C} / \mathrm{min}$ ) in another vacuum furnace (vacuum level: $\sim 10^{-6} \mathrm{mbar}$ ); the latter is part of a thermal test bench specifically built in-house in order to simulate an ISOL 
target during operation. This thermal testing bench consists of a resistively heated Ta tube $(\varnothing$ $2.5 \mathrm{~cm}$, length: $10 \mathrm{~cm}$, thickness: $0.2 \mathrm{~cm}$ ). In order to avoid chemical interaction between the $\mathrm{TaC}_{\mathrm{x}}$ discs and the heating tube, the discs were horizontally stacked and loaded into a graphite cell (POCO, nuclear reactor grade, high-purity graphite, France), specifically designed to fit in the cylindrical heating tube. This second furnace dedicated to high-temperature annealing will be referred to as " $C$ furnace". Current fluctuations in this high-temperature setup caused the actual temperature at the specimens' location to vary in the $2206-2254^{\circ} \mathrm{C}$ range, as detailed in the Supplementary Material. The discs were spaced by graphite foil to avoid sticking during annealing. In order to ensure that the setup was protected from the evaporation of small amounts of $\mathrm{Al}$ from residual $\mathrm{Ta}_{4} \mathrm{AlC}_{3} \mathrm{MAX}$ phase in the ceramics consolidated at $1500^{\circ} \mathrm{C}$, the heat treatments at $2200^{\circ} \mathrm{C}$ were performed on discs already pre-heated at $1850^{\circ} \mathrm{C}$, hence most of the residual $\mathrm{Al}$ has been extracted from these materials.

The high-temperature stability of the commercial $\mathrm{TaC}$ powder grades was assessed by heating them directly (heating rate: $\sim 20^{\circ} \mathrm{C} / \mathrm{min}$ ) to $1850^{\circ} \mathrm{C}$ for $2 \mathrm{~h}$ in the $\mathrm{W}$ furnace (heat treatment that also ensured their consolidation), as well as at $\sim 2200^{\circ} \mathrm{C}$ for $2 \mathrm{~h}$ and $12 \mathrm{~h}$ (heating rate: $\sim 20^{\circ} \mathrm{C} / \mathrm{min}$ ) in the $\mathrm{C}$ furnace.

\subsection{Characterization}

The materials were characterized by X-ray diffraction (XRD) patterns obtained in the $5-75^{\circ} 2 \theta$ range in steps of $0.01^{\circ}$ at $0.2 \mathrm{~s} / \mathrm{step}$, using a $\mathrm{Cu} \mathrm{K}_{\alpha}$ source operating at $30 \mathrm{kV}$ and $10 \mathrm{~mA}$ (Bruker D2 Phaser, Germany), in order to assess the phase composition of the produced grades before and after annealing. The scans were performed on the surface of the discs, and at different depths in a selected specimen. The XRD patterns were analysed by means of Rietveld refinement to determine the relative amount of phases in the binary $\mathrm{Ta}_{2} \mathrm{C}-\mathrm{TaC}_{\mathrm{x}}$ ceramics and the lattice parameter, $a$, of the cubic $\mathrm{TaC}_{\mathrm{x}}$ phase along with its stoichiometry, $\mathrm{x}$, according to the correlation $a=4.3007+0.1563 x$ [28]. The Rietveld refinements were performed using the MAUD software [31] (obtaining $R_{w p}$ values below $10 \%$ ).

Scanning electron microscopy combined with energy-dispersive X-ray spectroscopy (SEM/EDS; XL30-FEG, FEI, The Netherlands) was employed on polished and fractured surfaces in order to characterise the ceramic microstructures and verify the absence of residual Al or other contaminants. Electron backscattered diffraction (EBSD; Nova NanoSEM 450 instrument, FEI, The Netherlands) was used for phase and grain orientation mapping, as well as for the quantification of grain size distribution. More advanced imaging of the 3Dmicrostructure was done by micro-computed tomography $(\mu \mathrm{CT})$ on a Skyscan 1172 (Bruker, Kontich, Belgium) equipped with a W tube $(\lambda=0.024 \mathrm{~nm})$ and an $11 \mathrm{MP}$ detector. The resolution was set to $6.78 \mu \mathrm{m} / \mathrm{pixel}$ and the samples were rotated by $180^{\circ} \mathrm{C}$ with a rotation step size of $0.2^{\circ}$ and $\mathrm{Al} / \mathrm{Cu}$ filtering. Reconstruction was done by Nrecon 1.7.2 Client and Server (Bruker, Kontich, Belgium) and 3D-Visulisation by Amira 2020.1 (Thermofischer, Berlin, Germany).

The real density of each ceramic grade was determined by means of a helium $(\mathrm{He})$ pycnometer (Quantachrome MVP-6DC, USA) on crushed material, while the apparent (geometrical) density, $\rho$, of each ceramic grade before and after annealing was measured by means of the Archimedes method in ethanol, according to ASTM standard B962-17 [32]. The pore opening size distribution was determined by mercury $(\mathrm{Hg})$ intrusion porosimetry (MIP; Micrometrics 
AutoPore IV 9500, Germany), according to ASTM standard D4404-18 [33]. MIP was also used to determine the SSA, as described in the Supplementary Material [34-36].

The thermal conductivity and specific heat capacity were determined on square-shaped samples $\left(10 \times 10 \times 2 \mathrm{~mm}^{3}\right)$ by laser flash analysis, in a flowing $\mathrm{Ar}$ atmosphere up to $1000^{\circ} \mathrm{C}$, using a LFA 457 (Microflash, Netzsch Instruments, Selb, Germany). For the heat capacity calculation, an alumina $\left(\mathrm{Al}_{2} \mathrm{O}_{3}\right)$ standard of well-known heat capacity and the Netzsch Proteus Software (Version 6.0, Netzsch Instruments, Selb, Germany) were used. Before measurement, the samples were coated by a thin graphite layer. In assessing thermal conductivity, the material density was assumed constant with temperature.

\section{Results and discussion}

\subsection{Phase assembly}

In order to estimate the phase assembly (i.e., type and amount of present phases) of the $\mathrm{TaC}_{\mathrm{x}}$ grades, XRD patterns were obtained from the discs' surface after each heat treatment, revealing the two major binary carbide phases resulting from the decomposition of the $\mathrm{Ta}_{4} \mathrm{AIC}_{3}$ MAX phase in vacuum:

$\mathrm{Ta}_{4} \mathrm{AlC}_{3(\mathrm{~s})} \rightarrow 2 \mathrm{TaC}_{(\mathrm{s})}+\mathrm{Ta}_{2} \mathrm{C}_{(\mathrm{s})}+\mathrm{Al}_{(\mathrm{g})}$

The indexed XRD patterns shown in Fig. 2a identified cubic $\mathrm{TaC}_{\mathrm{x}}$ and trigonal $\alpha-\mathrm{Ta}_{2} \mathrm{C}$, as well as traces of residual $\mathrm{Ta}_{4} \mathrm{AlC}_{3} \mathrm{MAX}$ phase in the materials treated at the lower temperatures $\left(1500-1850^{\circ} \mathrm{C}\right)$. Table 2 provides the amount of hexagonal $\mathrm{Ta}_{2} \mathrm{C}$ and cubic $\mathrm{TaC}_{\mathrm{x}}$ phase on the discs' surface, as determined by Rietveld refinement in all grades, after all annealing heat treatments. The lattice parameter, $a$, and carbon content, $\mathrm{x}$, of the $\mathrm{TaC}_{\mathrm{x}}$ phase are also given. These non-destructive measurements estimated the phase composition and lattice properties on the disc's surface, whereas an accurate determination of the volume-averaged parameters can only be obtained by powder XRD analysis of crushed homogenised discs. Still, some considerations of the phase assembly and phase stoichiometry can be made in association with the Ta-C equilibrium phase diagram shown in Fig. 3 and adapted from [37]. The window probed in the present work is highlighted in Fig. 3: $1500<\mathrm{T}\left({ }^{\circ} \mathrm{C}\right)<2200$, and C stoichiometry, $x$, higher than that of the starting $\mathrm{Ta}_{4} \mathrm{AIC}_{3} \mathrm{MAX}$ phase, i.e., $\mathrm{x}>0.65$, considering that a substoichiometric $C$ content in the MAX phase allows for an $\mathrm{x}$ lower than the theoretical $\mathrm{x}=0.75$ in $\mathrm{Ta}_{4} \mathrm{AlC}_{3}$ [38].

The biphasic nature of the binary carbide obtained from the decomposition of the $\mathrm{Ta}_{4} \mathrm{AlC}_{3} \mathrm{MAX}$ phase was in agreement with previous results reported for the decomposition of bulk $\mathrm{Ta}_{4} \mathrm{AlC}_{3}$ at $1250^{\circ} \mathrm{C}$ in vacuum [27]. Noteworthy is the absence of the $\zeta-\mathrm{Ta}_{4} \mathrm{C}_{3-x}$ phase, although predicted in the $1157-2167^{\circ} \mathrm{C}$ temperature window by the Ta-C phase diagram at $\mathrm{C} / \mathrm{Ta} \approx 0.62$, and the absence of $\mathrm{Ta}_{6} \mathrm{C}_{5}$, as discussed previously [27]. In that prior study, the decomposition of bulk $\mathrm{Ta}_{4} \mathrm{AlC}_{3}$ at $1250^{\circ} \mathrm{C}$ was accompanied by the formation of large, inhomogeneously distributed pores and a thin crust of cubic $\mathrm{TaC}_{\mathrm{x}}$. In the present study, both $\mathrm{Ta}_{2} \mathrm{C}$ and $\mathrm{TaC}_{\mathrm{x}}$ phases were detected by XRD on the discs' surface after decomposition at $1500^{\circ} \mathrm{C}$ and annealing in the $\mathrm{W}$ furnace at the intermediate temperatures of $1600^{\circ} \mathrm{C}$ and $1850^{\circ} \mathrm{C}$. A slight difference in the amount of the trigonal $\alpha-\mathrm{Ta}_{2} \mathrm{C}$ phase was observed at lower temperatures. Moreover, at $1500^{\circ} \mathrm{C}$, a small amount $(<5 \mathrm{wt} \%)$ of residual $\mathrm{Ta}_{4} \mathrm{AlC}_{3}$ was still present. 

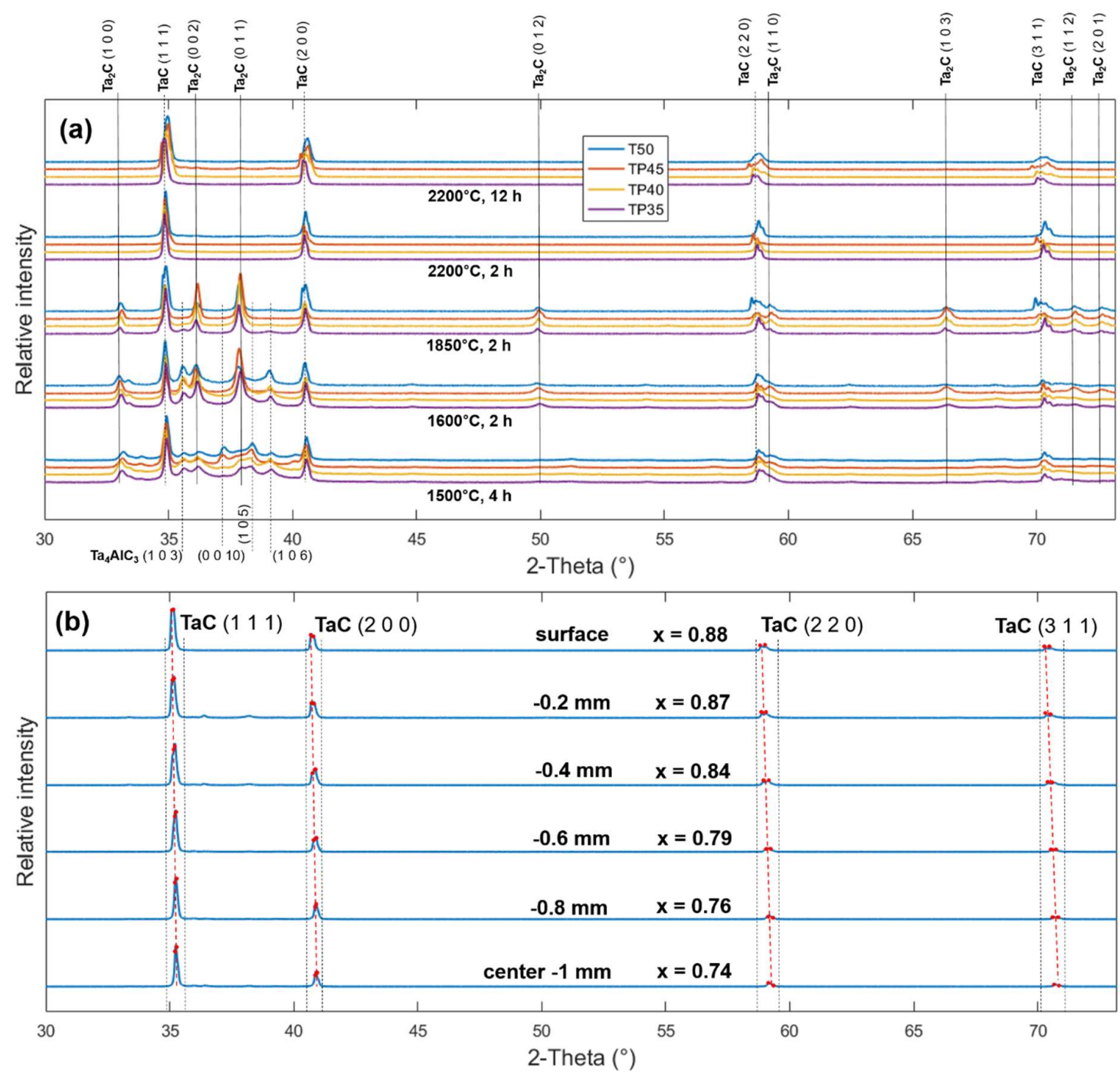

Fig. 2. (a) XRD patterns of the $\mathrm{Ta}_{4} \mathrm{AlC}_{3}$-based ceramic grades after different heat treatments. (b) High-angle $2 \theta$ cubic $\mathrm{TaC}_{\mathrm{x}}$ peak shifts as function of depth from the surface of the T50 grade after annealing at $2200^{\circ} \mathrm{C}$ for $12 \mathrm{~h}$, due to a gradient in the $\mathrm{C}$ content.

As suggested by the XRD patterns in Fig. 2a, the trigonal $\alpha-\mathrm{Ta}_{2} \mathrm{C}$ peaks disappeared gradually from the surface of all ceramic grades, as the annealing temperature increased. The $\mathrm{TaC}_{\mathrm{x}}$ content varied in the $49-65 \mathrm{wt} \%$ range in the grades that had been annealed in the $\mathrm{W}$ furnace between $1500^{\circ} \mathrm{C}$ and $1850^{\circ} \mathrm{C}$ (see Table 2). The cubic $\mathrm{TaC}_{x}$ phase on the disc surface became prevalent after annealing at $2200^{\circ} \mathrm{C}$ in the $\mathrm{C}$ furnace, without significant difference between the heat treatments conducted for $2 \mathrm{~h}$ and $12 \mathrm{~h}$. The lattice parameters of the trigonal $\alpha-\mathrm{Ta}_{2} \mathrm{C}$ phase were found to be $a=(3.105 \pm 0.002) \AA$ and $c=(4.941 \pm 0.001) \AA$, as determined by Rietveld refinement and in accordance with literature: $a_{\text {lit }}=(3.1030 \pm 0.0001) \AA$ and $c_{\text {lit }}=$ $(4.9378 \pm 0.0001) \AA$ [39]. 


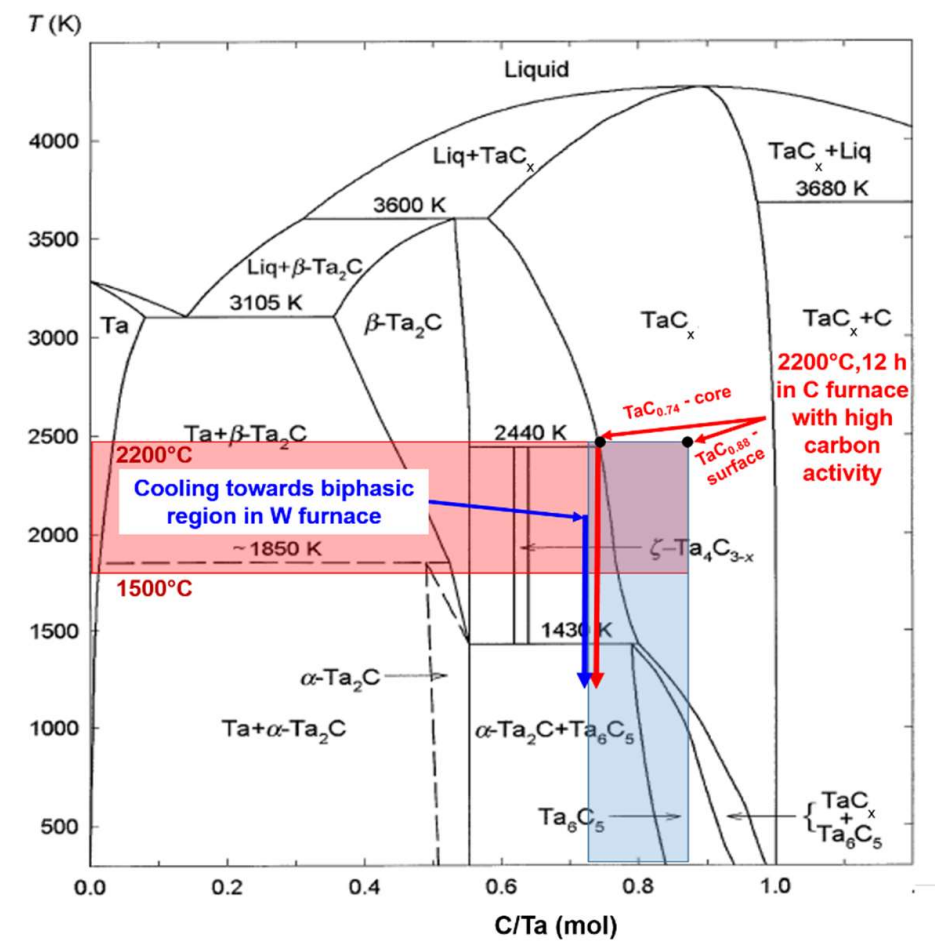

Fig. 3. Ta-C equilibrium phase diagram (adapted from [37]). The blue window highlights the carbon content range explored in the present work, whereas the red window denotes the temperature window of the various annealing heat treatments performed in this work.

An increased cubic $\mathrm{TaC}_{\mathrm{x}}$ phase content is expected at higher temperatures, according to the Ta-C equilibrium phase diagram, within the investigated temperature window, for a starting powder stoichiometry of $x=0.65-0.70$. The fact that $\mathrm{Ta}_{2} \mathrm{C}$ was no longer observed in the XRD patterns of the disc surface can be attributed to the addition of $\mathrm{C}$ as result of the presence of the graphite inserts and the spacing foils surrounding the specimens in the $C$ furnace during annealing at $2200^{\circ} \mathrm{C}$. The lattice parameters of the cubic $\mathrm{TaC}_{\mathrm{x}}$ phase detected on the surface evolved in stoichiometry over the $0.79<x<0.88$ range, increasing with increasing temperature. This is a clear evidence of the role of $\mathrm{C}$ pick-up from the graphite present in the furnace. If the $\mathrm{C}$ content in the system was constant, the stoichiometry of the cubic $\mathrm{TaC}_{\mathrm{x}}$ equilibrium phase would decrease with increasing temperature, according to the Ta-C phase diagram.

A single study of the evolution of the $\mathrm{TaC}_{x}$ phase stoichiometry was conducted by collecting XRD patterns at different depths from the disc's surface in a particularly representative sample, which was expected to be carburised due to the contact with a graphite support material, i.e., the T50 grade annealed for $12 \mathrm{~h}$ at $2200^{\circ} \mathrm{C}$. XRD patterns were obtained at different depths by grinding the material in progressive steps of $0.2 \mathrm{~mm}$ until the middle of the disc. The result of the depth profile XRD study is shown in Fig. $2 b$, where the high-2 $\theta$ peaks corresponding to the (111), (200), (220) and (311) reflections shift to higher $2 \theta$ angles with increasing depth, as a result of the decreased $C$ content $x$. The $C$ stoichiometry, $x$, calculated from lattice parameter $a$ decreased from $\mathrm{x}=0.88$ at the surface to $\mathrm{x}=0.74$ in the core. This is due to the $C$ enrichment of the disc surface in the $C$ furnace, due to the graphite insert and the graphite foil spacers around the specimens. In the study of TiC-carbon composite target materials, similar alteration of the $\mathrm{C}$ amount was observed as a consequence of heat combined with the presence of a $\mathrm{C}$ 
source [6]. In the core of the disc, where the material was not directly exposed to $C$, the $\mathrm{TaC}_{\mathrm{x}}$ stoichiometry was that of the boundary in the $\mathrm{Ta}-\mathrm{C}$ phase diagram at $2200^{\circ} \mathrm{C}$, i.e., $\mathrm{TaC}_{0.74}$. It should also be highlighted that in this material, which was annealed at $2200^{\circ} \mathrm{C}$ for $12 \mathrm{~h}$, no trigonal $\mathrm{Ta}_{2} \mathrm{C}$ was detected.

\section{Table 2}

Summary of estimated amount of $\mathrm{Ta}_{2} \mathrm{C}$ and $\mathrm{TaC}_{\mathrm{x}}$ phases, lattice parameter $(a)$, and carbon $(\mathrm{x})$ content of $\mathrm{TaC}_{\mathrm{x}}$ on the disc surface, and theoretical density (TD) measured by pycnometry, density measured by Archimedes method and \%TD for each given grade and heat treatment.

\begin{tabular}{|c|c|c|c|c|c|c|c|c|}
\hline \multirow[b]{2}{*}{ Grade } & \multirow[b]{2}{*}{$\begin{array}{l}\text { heat } \\
\text { treatment }\end{array}$} & \multicolumn{4}{|c|}{ surface XRD data } & \multirow{2}{*}{$\begin{array}{c}\text { pycnometer } \\
\text { density } \\
\left(\mathrm{g} / \mathrm{cm}^{3}\right)\end{array}$} & \multirow[b]{2}{*}{$\begin{array}{l}\text { density } \\
\left(\mathrm{g} / \mathrm{cm}^{3}\right)\end{array}$} & \multirow[b]{2}{*}{$\%$ TD } \\
\hline & & $\begin{array}{l}\mathrm{wt} \% \\
\mathrm{Ta}{ }_{2} \mathrm{C}\end{array}$ & $\begin{array}{l}\text { wt } \% \\
\mathrm{TaC}_{\mathrm{x}}\end{array}$ & $\begin{array}{c}a\left(\mathrm{TaC}_{\mathrm{x}}\right) \\
(\AA)\end{array}$ & $\begin{array}{c}x \text { in } \\
\left(\mathrm{TaC}_{\mathrm{x}}\right)\end{array}$ & & & \\
\hline \multirow{4}{*}{ T50 } & $1500^{\circ} \mathrm{C}, 4 \mathrm{~h}$ & 33 & 54 & 4.4243 & 0.79 & \multirow{16}{*}{$12.02 \pm 0.004$} & 6.39 & 53.2 \\
\hline & $1850^{\circ} \mathrm{C}, 2 \mathrm{~h}$ & 34 & 65 & 4.423 & 0.78 & & 6.78 & 56.4 \\
\hline & $2200^{\circ} \mathrm{C}, 2 \mathrm{~h}$ & 6.6 & 93.4 & \multirow{2}{*}{4.4368} & \multirow{2}{*}{0.88} & & $7.1 \pm 0.5$ & 59.1 \\
\hline & $2200^{\circ} \mathrm{C}, 12 \mathrm{~h}$ & 0 & 100 & & & & $6.97 \pm 0.4$ & 58,0 \\
\hline \multirow{4}{*}{ TP45 } & $1500^{\circ} \mathrm{C}, 4 \mathrm{~h}$ & 34 & 50 & 4.4272 & 0.82 & & 5.88 & 48.9 \\
\hline & $1850^{\circ} \mathrm{C}, 2 \mathrm{~h}$ & 42 & 54 & 4.423 & 0.78 & & 6.07 & 50.5 \\
\hline & $2200^{\circ} \mathrm{C}, 2 \mathrm{~h}$ & 1 & 99 & \multirow{2}{*}{4.4318} & \multirow{2}{*}{0.84} & & $6.69 \pm 0.7$ & 55.7 \\
\hline & $2200^{\circ} \mathrm{C}, 12 \mathrm{~h}$ & 0 & 100 & & & & $6.75 \pm 0.4$ & 56.1 \\
\hline \multirow{4}{*}{ TP40 } & $1500^{\circ} \mathrm{C}, 4 \mathrm{~h}$ & 37 & 50 & 4.4294 & 0.82 & & 4.8 & 39.9 \\
\hline & $1850^{\circ} \mathrm{C}, 2 \mathrm{~h}$ & 44 & 54 & 4.4231 & 0.78 & & 5.06 & 42.1 \\
\hline & $2200^{\circ} \mathrm{C}, 2 \mathrm{~h}$ & 2 & 98 & \multirow{2}{*}{4.4354} & \multirow{2}{*}{0.86} & & $6.11 \pm 0.6$ & 50.8 \\
\hline & $2200^{\circ} \mathrm{C}, 12 \mathrm{~h}$ & 0 & 100 & & & & $5.81 \pm 0.5$ & 48.3 \\
\hline \multirow{4}{*}{ T35 } & $1500^{\circ} \mathrm{C}, 4 \mathrm{~h}$ & 39 & 49 & 4.4315 & 0.84 & & 4.29 & 35.7 \\
\hline & $1850^{\circ} \mathrm{C}, 2 \mathrm{~h}$ & 47 & 52 & 4.423 & 0.78 & & 4.52 & 37.6 \\
\hline & $2200^{\circ} \mathrm{C}, 2 \mathrm{~h}$ & 3.3 & 96.7 & \multirow{2}{*}{4.4304} & \multirow{2}{*}{0.83} & & $4.97 \pm 0.4$ & 41.3 \\
\hline & $2200^{\circ} \mathrm{C}, 12 \mathrm{~h}$ & 0 & 100 & & & & $4.97 \pm 0.3$ & 41.3 \\
\hline \multirow{3}{*}{ TC50 } & $1850^{\circ} \mathrm{C}, 2 \mathrm{~h}$ & 0 & 100 & \multirow{3}{*}{4.4563} & \multirow{3}{*}{1} & \multirow{12}{*}{$11.23 \pm 0.07$} & $\begin{array}{c}6.79 \pm \\
0.27\end{array}$ & 60.5 \\
\hline & $2200^{\circ} \mathrm{C}, 2 \mathrm{~h}$ & 0 & 100 & & & & $\begin{array}{c}6.67 \pm \\
0.13\end{array}$ & 59.4 \\
\hline & $2200^{\circ} \mathrm{C}, 12 \mathrm{~h}$ & 0 & 100 & & & & $\begin{array}{c}6.68 \pm \\
0.47\end{array}$ & 59.5 \\
\hline \multirow{3}{*}{ TCP45 } & $1850^{\circ} \mathrm{C}, 2 \mathrm{~h}$ & 0 & 100 & \multirow{3}{*}{4.491} & \multirow{3}{*}{1.01} & & $\begin{array}{c}6.15 \pm \\
0.25 \\
\end{array}$ & 54.8 \\
\hline & $2200^{\circ} \mathrm{C}, 2 \mathrm{~h}$ & 0 & 100 & & & & $\begin{array}{c}6.27 \pm \\
0.25 \\
\end{array}$ & 55.8 \\
\hline & $2200^{\circ} \mathrm{C}, 12 \mathrm{~h}$ & 0 & 100 & & & & $6.1 \pm 0.37$ & 54.3 \\
\hline \multirow{3}{*}{ TCP40 } & $1850^{\circ} \mathrm{C}, 2 \mathrm{~h}$ & 0 & 100 & \multirow{3}{*}{4.4595} & \multirow{3}{*}{1.02} & & $\begin{array}{c}5.55 \pm \\
0.22\end{array}$ & 49.4 \\
\hline & $2200^{\circ} \mathrm{C}, 2 \mathrm{~h}$ & 0 & 100 & & & & $6.1 \pm 0.31$ & 54.3 \\
\hline & $2200^{\circ} \mathrm{C}, 12 \mathrm{~h}$ & 0 & 100 & & & & $\begin{array}{c}6.12 \pm \\
0.24 \\
\end{array}$ & 54.5 \\
\hline \multirow{3}{*}{ TCP35 } & $1850^{\circ} \mathrm{C}, 2 \mathrm{~h}$ & 0 & 100 & & & & $\begin{array}{c}5.39 \pm \\
0.11 \\
\end{array}$ & 48.1 \\
\hline & $2200^{\circ} \mathrm{C}, 2 \mathrm{~h}$ & 0 & 100 & 4.4595 & 1.02 & & $\begin{array}{c}5.87 \pm \\
0.29\end{array}$ & 52.3 \\
\hline & $2200^{\circ} \mathrm{C}, 12 \mathrm{~h}$ & 0 & 100 & & & & $5.97 \pm 0.3$ & 53.2 \\
\hline
\end{tabular}

\subsection{Microstructure}

By comparing the dimensions of the discs before and after sintering at $1500^{\circ} \mathrm{C}$ for $2 \mathrm{~h}$, an overall linear volumetric shrinkage of only $0.4 \%$ was measured. After annealing at $2200^{\circ} \mathrm{C}$, a 
$4 \%$ volumetric shrinkage was found, which must be taken into account during manufacturing of an ISOL target for long-term operation. The densities of the produced grades were measured by the Archimedes method and are shown in Table 2, where the targeted overall $\%$ TD of each grade is compared with the measured (geometrical) density, $\rho$, and actual \%TD after each heat treatment. The calculation of the \%TD was performed by relating the apparent density to the theoretical density of the dense material, measured by He pycnometry on crushed specimens and reported in Table 2. Details over the employed Archimedes method are given in the Supplementary Material.

The materials were also characterized by MIP in order to determine the distribution of the width of the pore connections (not identical to the pore size diameter), herein referred to as "cell window opening size". The diameter of the window between two pores is usually smaller than the diameter of the connected pores, and the $\mathrm{Hg}$ intrusion pressure needed to get through a particular window size is inversely proportional to the size. This window can be treated as a cylindrical volume in a first approximation, so that the Washburn equations can be applied.
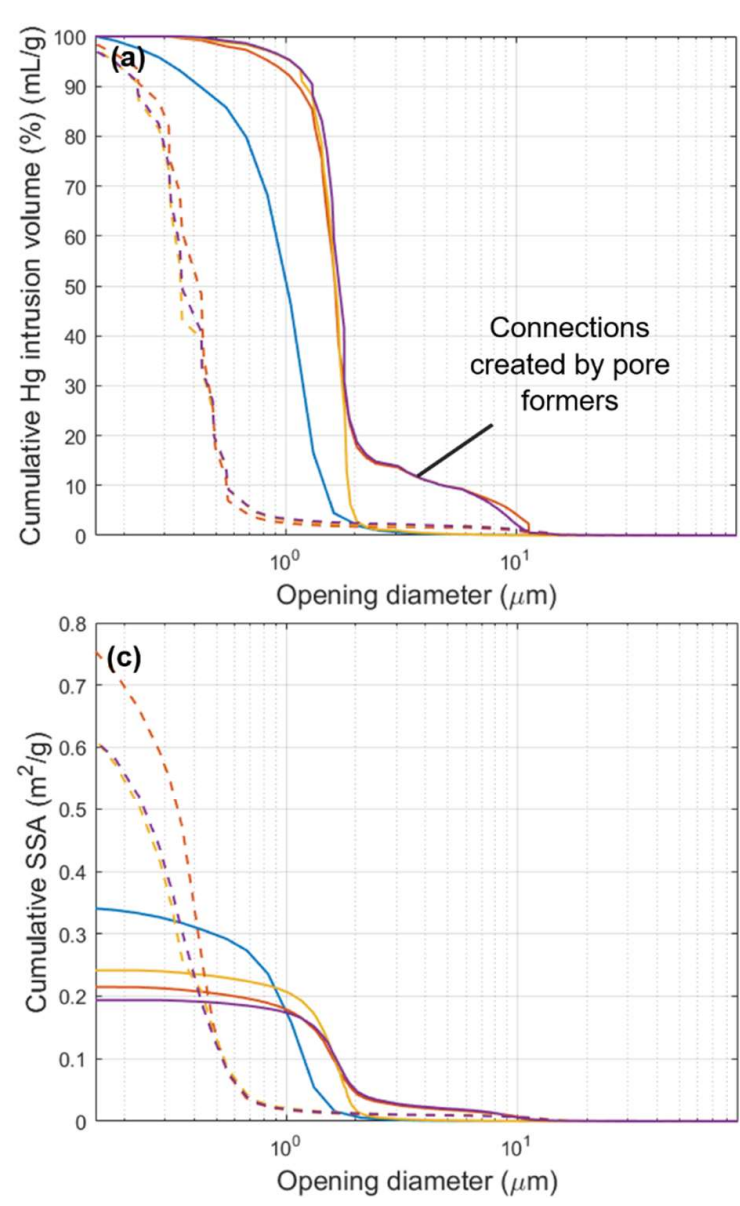
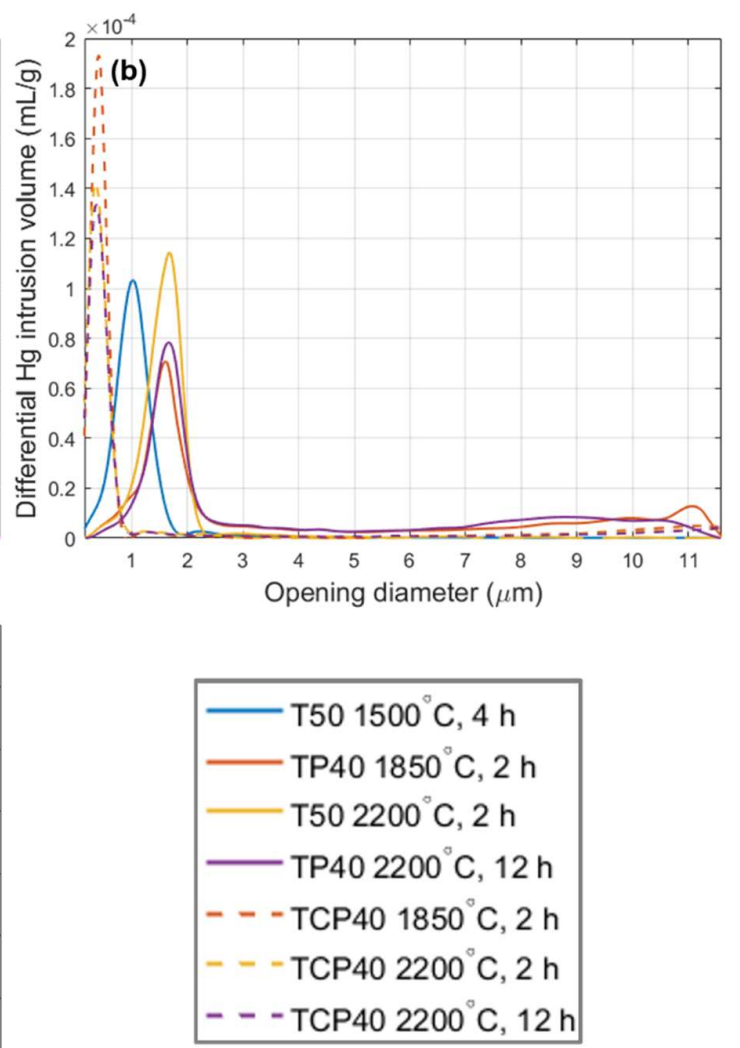

Fig. 4. MIP measurements corresponding to different pore opening diameters: (a) cumulative $\mathrm{Hg}$ intrusion volume, (b) differential $\mathrm{Hg}$ intrusion volume, and (c) cumulative SSA as function of the cell window opening size. 
The results are presented as function of the cell window opening size for the cumulative $\mathrm{Hg}$ intrusion volume in Fig. $4 \mathrm{a}$, the differential $\mathrm{Hg}$ intrusion volume for micrometric $(<12 \mu \mathrm{m})$ pores in Fig. 4b, and the cumulative SSA in Fig. 4c. This analysis was conducted on select samples, i.e., T50 and TP40, in order to assess the effect of the pore-formers (present in TP40, but not in T50) after annealing at 1500,1850 and $2200^{\circ} \mathrm{C}$. The curves in Fig. 4a represent the progressive accumulation of material volume intruded by $\mathrm{Hg}$. $\mathrm{Hg}$ pumped into the material under increasing pressure first intrudes the larger cell windows, followed by the smaller ones, as a higher pressure is needed to overcome the increasing surface tension of $\mathrm{Hg}$ in its attempt to pass through progressively smaller cell windows. The steep increase observed for these curves corresponds to critical pore sizes, where filling by $\mathrm{Hg}$ occurs. The most significant increase was observed at cell window sizes in the 1-1.7 $\mu \mathrm{m}$ range, which correspond to the macroporous network. In the TCP40 reference grade, the onset of intrusion corresponds to cell window sizes below $1 \mu \mathrm{m}$. No connectivity of the large cavities resulting from the addition of pore-formers was detected in the TCP40 grade, as opposed to the TP40 grade (Fig. 4a and 4b).

The T50 grade (annealed at $1500^{\circ} \mathrm{C}$ for $4 \mathrm{~h}$ ) had a monomodal cell window size distribution around $1 \mu \mathrm{m}$, as shown in the plot of Fig. 4b. The TP40 grades (annealed at both $1850^{\circ} \mathrm{C}$ for $2 \mathrm{~h}$, and at $2200^{\circ} \mathrm{C}$ for $12 \mathrm{~h}$ ), with pore-formers added during processing, are characterised by porosity with an average cell window size of $1.6-1.7 \mu \mathrm{m}$, while roughly $20 \%$ of the intruded volume is due to the presence of larger openings in the 2-10 $\mu \mathrm{m}$ range (Fig. 4a); the latter are directly attributed to the presence of the larger cavities formed by the interconnected poreformers. Heating from $1850^{\circ} \mathrm{C}$ to $2200^{\circ} \mathrm{C}$ did not alter significantly the bimodal pore structure, leading to the same relative cumulative intrusion profiles, as shown in Fig. 4a and Fig. 4b. However, one may notice a slightly increased cell window size in the base macroporous network (i.e., without PA pore-formers), due to the loss of smaller pores (e.g., compare T50 annealed for $4 \mathrm{~h}$ at $1500^{\circ} \mathrm{C}$ and for $2 \mathrm{~h}$ at $2200^{\circ} \mathrm{C}$, Fig. $4 \mathrm{~b}$ ). This reflects the minor alteration of the base pore network as the temperature increases, promoting pore spheroidisation, merging and interconnectivity. Fig. 4c shows the evolution of the SSA, which reaches a maximum of $0.34 \mathrm{~m}^{2} / \mathrm{g}$ in T50 (annealed at $1500^{\circ} \mathrm{C}$ for $4 \mathrm{~h}$ ), dropping to $0.25 \mathrm{~m}^{2} / \mathrm{g}$ in T50 annealed at $2200^{\circ} \mathrm{C}$ for $2 \mathrm{~h}$, due to the slight densification of the macroporous 'matrix'.

The fact that no major change in porosity was observed between the materials annealed for 2 $\mathrm{h}$ and $12 \mathrm{~h}$ at $2200^{\circ} \mathrm{C}$ (e.g., TP40 in Fig. 4a) is in accordance with the macroscopic density observations. The slight changes in density resulting from annealing at $1500^{\circ} \mathrm{C}$ and $2200^{\circ} \mathrm{C}$ observed by both Archimedes method and MIP are to be mainly attributed to changes in the base pore microstructure and not to the larger pores generated by the PA pore-formers. In other words, the cavities introduced by the PA spheres are too large to undergo shrinkage by matrix sintering. This also explains the consistent shift towards higher density values as the temperature increases, since the densification behaviour of TP45, TP40 and TP35 is similar to that of T50 without pore-formers. It might be anticipated that the bimodal pore size distribution will remain stable even at longer operation times at $2200^{\circ} \mathrm{C}$. The TCP40 reference grade had an average pore opening of $0.4 \mu \mathrm{m}$ at $1850^{\circ} \mathrm{C}$, which reduced to $0.36 \mu \mathrm{m}$ after annealing at $2200^{\circ} \mathrm{C}$ (Fig. $4 \mathrm{~b}$ ), with a decrease in total amount of intruded $\mathrm{Hg}$ by $\sim 28 \%$ (Fig. 4a). The SSA of the TCP40 reference grade was appreciably higher than in the examined TP grades, being $0.7 \mathrm{~m}^{2} / \mathrm{g}$ after $2 \mathrm{~h}$ at $1850^{\circ} \mathrm{C}$, and decreasing to $0.6 \mathrm{~m}^{2} / \mathrm{g}$ after $12 \mathrm{~h}$ at $2200^{\circ} \mathrm{C}$, which is consistent with the decrease in pore opening size for the base pore microstructure and its slight observed densification. 

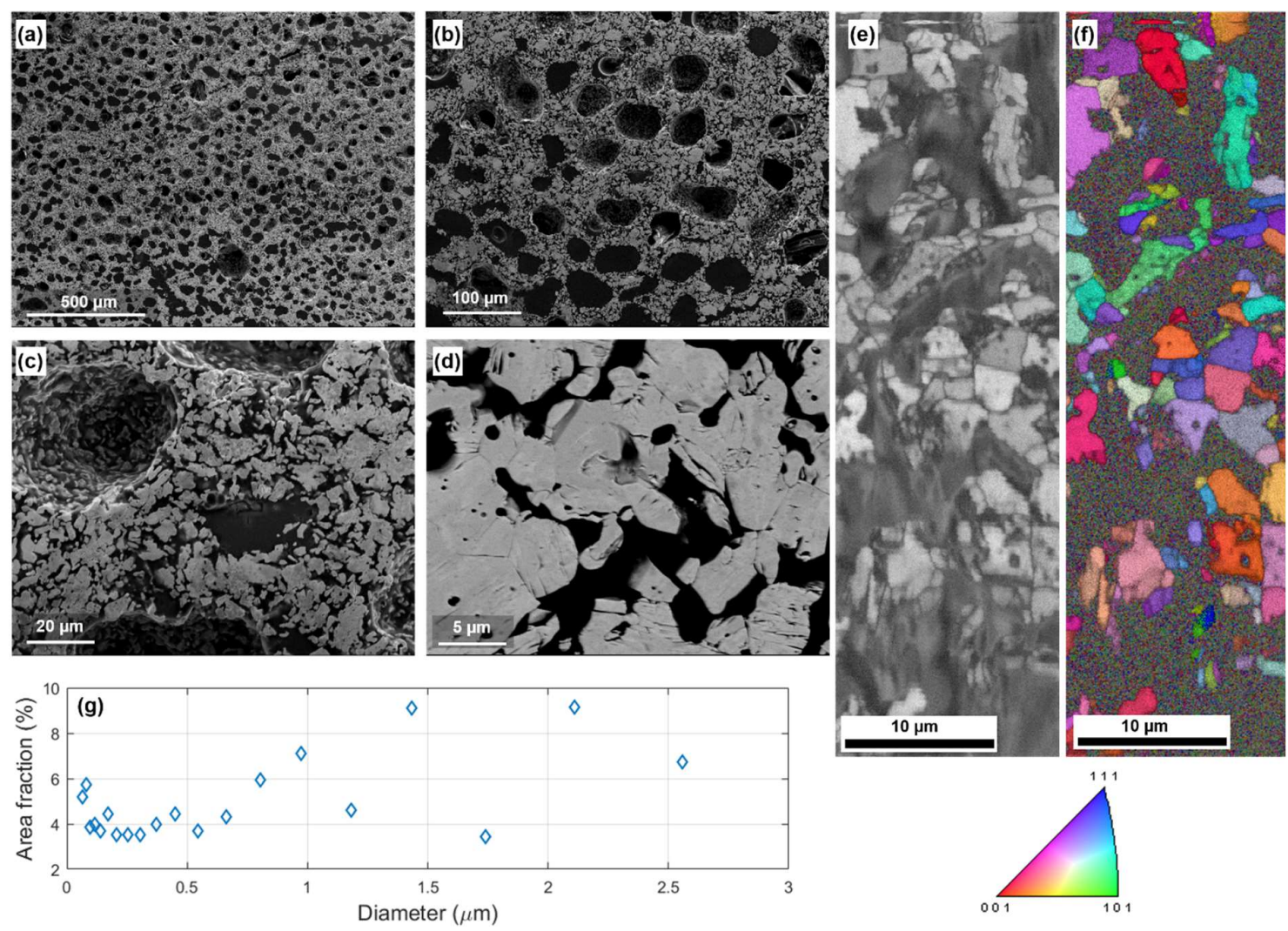

Fig. 5. Microstructural characterisation of TP35 after annealing at $2200^{\circ} \mathrm{C}$ for $12 \mathrm{~h}$; polished cross-section. SEM data: (a) backscattered electron (BSE) image of the porous matrix; (b,c,d) secondary electron (SE) images of the distribution of the larger pores due to the addition of PA spheres, at different magnifications. EBSD data: (e) BSE image of the scanned area; (f) EBSD grain orientation map of this area (the dark, non-indexed areas correspond to porosity; the inverse pole figure colour map for cubic $\mathrm{TaC}_{\mathrm{x}}$ is also given); and $(\mathrm{g})$ grain size distribution of the scanned area computed by the EDAX software.

When developing ISOL target materials, one typically strives for smaller particle/grain size and higher SSA, since they are both advantageous in terms of isotope release [7]. Based on the SSA, reference grades produced from commercial TaC powder are preferred over grades derived from the precursor $\mathrm{Ta}_{4} \mathrm{AIC}_{3} \mathrm{MAX}$ phase powder, which has $30 \%$ lower SSA at ISOL operating temperatures due to its coarser starting particle size (e.g., compare TP40 with TCP40 grades annealed for $12 \mathrm{~h}$ at $2200^{\circ} \mathrm{C}$, Fig. 4c). The obtained SSA values can be compared to SSA values reported in similar work on $\mathrm{TiC}$ and $\mathrm{TiC}+$ carbon black (CB) composite target materials obtained from compacts of nanometric TiC powder [5]. In that study, the SSA values were measured by Brunauer-Emmett-Teller (BET) nitrogen $\left(\mathrm{N}_{2}\right)$ gas adsorption both after compaction and after annealing at $1800^{\circ} \mathrm{C}$ for $10 \mathrm{~h}$. While starting from SSA values (i.e., $29.1 \mathrm{~m}^{2} / \mathrm{g}$ in pure $\mathrm{TiC}$, and $30 \mathrm{~m}^{2} / \mathrm{g}$ in $\mathrm{TiC}+\mathrm{CB}$ composites) that were considerably higher than those measured on mould-casted $\mathrm{TaC}_{\mathrm{x}}$ in the present study, the reduction after annealing was significant (i.e., $99.6 \%$ in $\mathrm{TiC}$ and $54.4 \%$ in $\mathrm{TiC}+\mathrm{CB}$ ). It must be considered that this study was conducted on materials obtained from submicrometer starting powders, where high reduction in the SSA is expected due to the large driving force for sintering. The observed difference in SSA loss was attributed to the fact that the CB addition 
inhibited further sintering. The process presented in the present study proved that, despite the fact that the obtained porous $\mathrm{TaC}_{\mathrm{x}}$ ceramics show SSA values $<1 \mathrm{~m}^{2} / \mathrm{g}$, they remain relatively stable for several hours (up to $12 \mathrm{~h}$ ) at the highest annealing temperature $\left(2200^{\circ} \mathrm{C}\right.$ ). This is generally promising when one aims at maintaining a stable isotope release over long operation times, although the quantification of such advantage must be determined by direct irradiation and release tests.

The mould-casted $\mathrm{Ta}_{4} \mathrm{AlC}_{3}$ based ceramics had a highly open porous microstructure after all conducted heat treatments. SEM micrographs obtained from a metallographic cross-section of annealed $\left(2200^{\circ} \mathrm{C}\right.$ for $\left.12 \mathrm{~h}\right)$ TP35 in Figs. $5 \mathrm{a}, 5 \mathrm{~b}$ and $5 \mathrm{c}$ reveal the stable bimodal pore size distribution created by the addition of the PA spheres to the master feedstock. Details of the base matrix are revealed in Fig. $5 \mathrm{c}$ (scale showing the bimodal pore size distribution) and Fig. $5 d$ (scale close to the particle size). The microstructure shown in Fig. $5 d$ results from localized sintering by neck formation and grain boundary diffusion at the high annealing temperature of $2200^{\circ} \mathrm{C}$. The grain size is comparable to the average particle size of the starting (as-milled) $\mathrm{Ta}_{4} \mathrm{AlC}_{3}$ powder $(\sim 4 \mu \mathrm{m})$. EBSD was used on the same polished metallographic cross-section of annealed $\left(12 \mathrm{~h}, 2200^{\circ} \mathrm{C}\right)$ TP35. A backscattered electron (BSE) SEM image of the mapped by EBSD area is shown in Fig. 5e, while the EBSD grain orientation map, along with the inverse pole figure colour maps for cubic $\mathrm{TaC}_{\mathrm{x}}$ is shown in Fig. 5f. The noisy (non-indexed) areas in the EBSD grain orientation map correspond to porosity, whereas the coloured regions are cubic $\mathrm{TaC}_{\mathrm{x}}$ grains. This kind of imaging depicts the grain size and orientation in the porous matrix, providing additional information on the microstructure of the porous ceramics than conventional SEM. Material regions of up to $\sim 10 \mu \mathrm{m}$ in size appear to consist of clusters of up to six grains with stable grain boundary configurations. The grain size distribution in Fig. $5 \mathrm{~g}$ shows that the largest fraction of the grains is smaller than $1 \mu \mathrm{m}$ and the maximum detected grain size is $2.56 \mu \mathrm{m}$, i.e., slightly smaller than the average particle size of the starting $\mathrm{Ta}_{4} \mathrm{AlC}_{3}$ MAX phase precursor.

The SEM images of the fracture surfaces of TP35 in Fig. 6 show the microstructural evolution after annealing in the $\mathrm{W}$ and $\mathrm{C}$ furnace. The reference TC50 and TCP35 grades, produced from commercial TaC powder, are also presented for comparison after annealing for $2 \mathrm{~h}$ at $1850^{\circ} \mathrm{C}$ (Figs. 6e and 6f) and for $12 \mathrm{~h}$ at $2200^{\circ} \mathrm{C}$ (Figs. 6k and 6I). These micrographs compare both the base porous network ( $a, b$, and e) and the bimodal pore size distribution (c, d, and f). As the annealing temperature increased from $1500^{\circ} \mathrm{C}$ and $1850^{\circ} \mathrm{C}$ in the $\mathrm{W}$ furnace and up to $2200^{\circ} \mathrm{C}$ in the $\mathrm{C}$ furnace, the pore wall structure became smoother, but the open porosity was retained. This could be associated with an increased neck formation in the ligaments between pores, due to the merging of smaller pores into larger, stable pore structures. Qualitatively, no major densification effects were observed by SEM imaging. Cavities with size in the 10-70 $\mu \mathrm{m}$ range were generally stable and appeared to be unaffected by annealing. The addition of sacrificial pore-formers proved to be a successful way to generate a bimodal porous distribution in the material, i.e., a microporous matrix with a dispersion of larger cavities that can expedite the effusion of species close to the surface of the target material as compared to a material of which the porosity is only attributed to a base porous network (e.g., grade T50). At the SPES ISOL facility under construction in Legnaro, Italy, a similar technique was applied by adding sacrificial poly methyl methacrylate (PMMA) fibres to lanthanum oxycarbide and carbide materials, increasing the overall material permeability by five orders of magnitude (for a high-pressure regime of target operating conditions), due to the increased interconnectivity of permeable paths [40-42]. 
The reference grades produced from commercial TaC powders showed a much finer base microstructure with smaller pores and a lack of interconnectivity between the large pores introduced by the PA pore-formers. Large cavities are also less numerous in the TC grades, probably due to a lower powder particle packing stability during the pyrolysis step, where the surrounding scaffold of fine $\mathrm{TaC}$ powder particles could have collapsed, filling some of the cavities. No microstructural differences were observed as result of an increase in annealing temperature from $1850^{\circ} \mathrm{C}$ to $2200^{\circ} \mathrm{C}$.
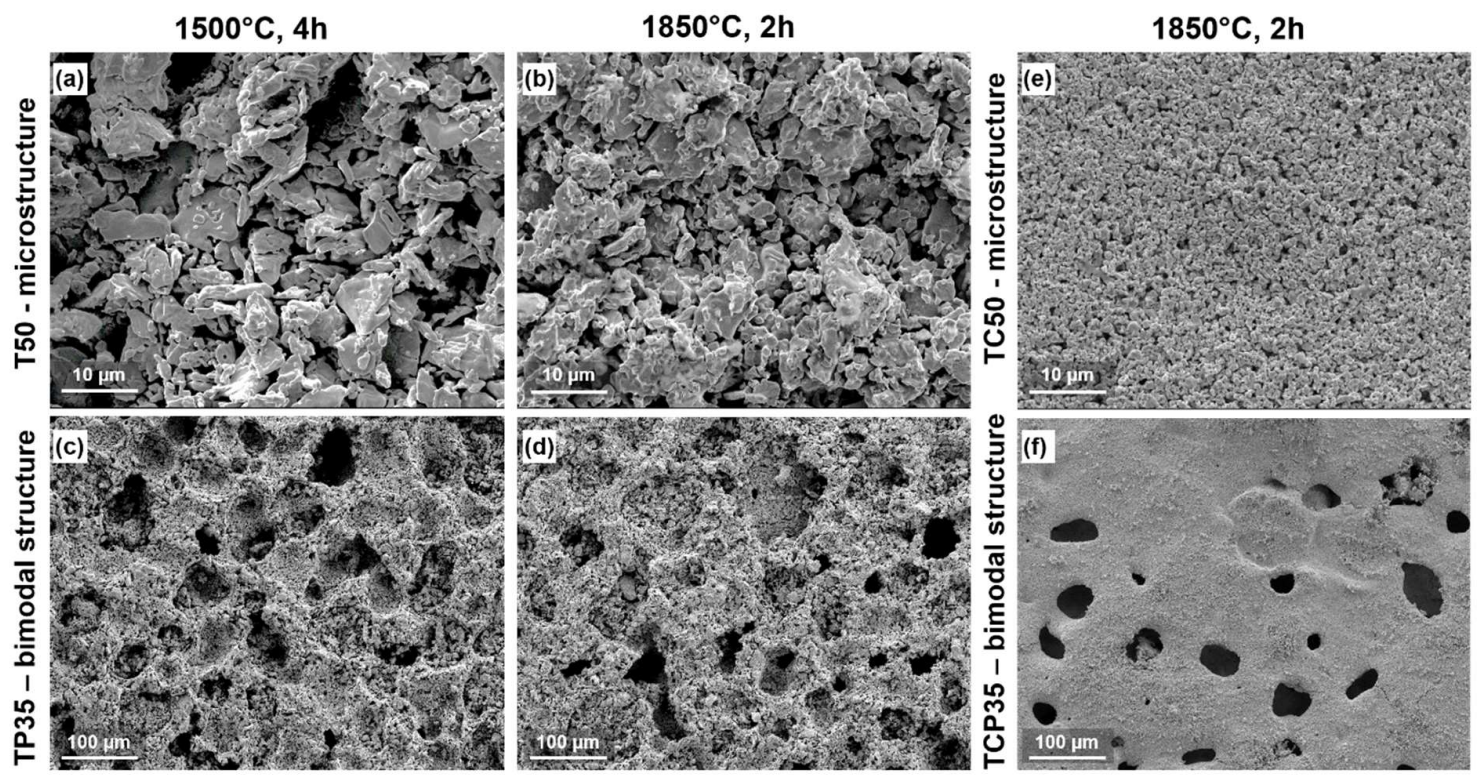

$2200^{\circ} \mathrm{C}, 2 \mathrm{~h}$

$2200^{\circ} \mathrm{C}, 12 \mathrm{~h}$
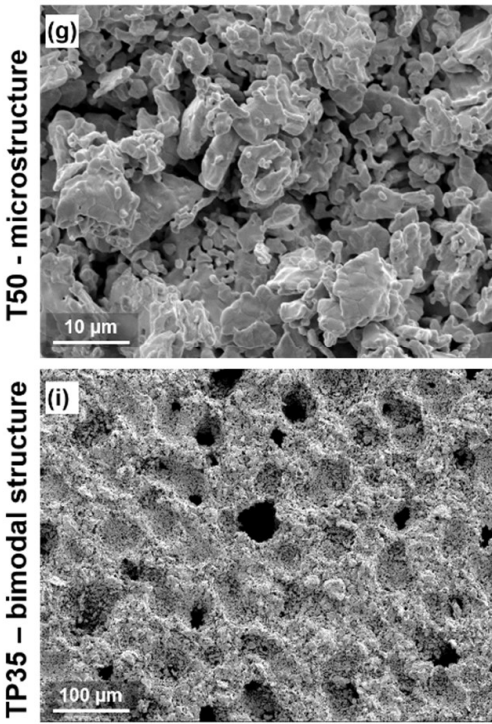
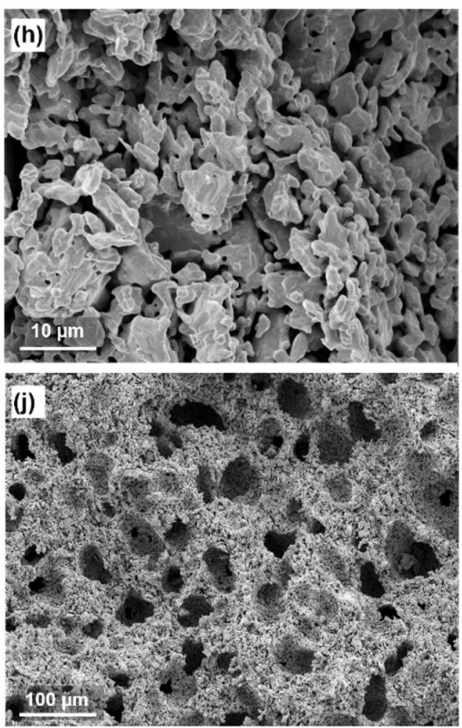

$2200^{\circ} \mathrm{C}, 12 \mathrm{~h}$
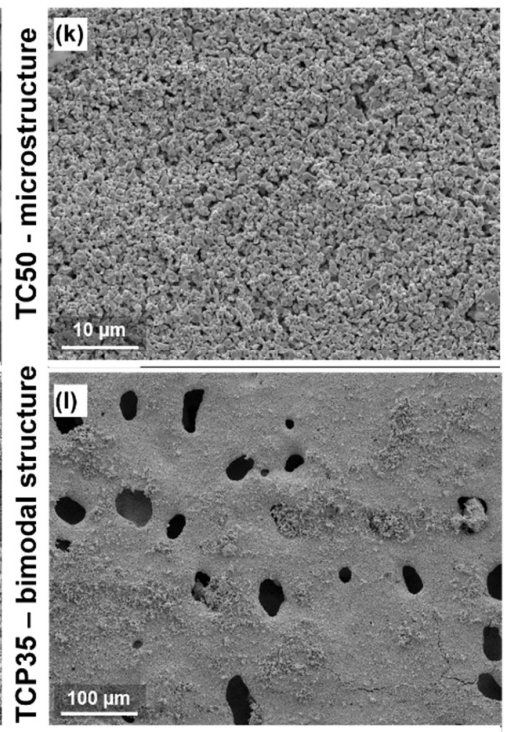

Fig. 6. SE images of the macroporous matrix and bimodal pore size in fractured T50 and TP35, respectively, after annealing in the $W$ furnace for $4 \mathrm{~h}$ at $1500^{\circ} \mathrm{C}(\mathrm{a}, \mathrm{C})$ and $2 \mathrm{~h}$ at $1850^{\circ} \mathrm{C}(\mathrm{b}, \mathrm{d})$. SE images of the porous structure in fractured TC50 (e) and TCP35 (f) annealed for $2 \mathrm{~h}$ at $1850^{\circ} \mathrm{C}$ in the W furnace. SE images of fractured T50 and TP35, respectively, after annealing 
in the $\mathrm{C}$ furnace at $2200^{\circ} \mathrm{C}$ for $2 \mathrm{~h}(\mathrm{~g}, \mathrm{i})$ and $12 \mathrm{~h}(\mathrm{~h}, \mathrm{j})$. SE images of the porous structure in fractured TC50 (k) and TCP35 (I) annealed at $2200^{\circ} \mathrm{C}$ for $12 \mathrm{~h}$ in the $\mathrm{C}$ furnace.

The density and MIP measurements in Fig. 4 correlate well with the microstructural features shown in the SEM micrographs of Figs. 5 and 6 . In the $1500-1850^{\circ} \mathrm{C}$ temperature range, the obtained \%TD exceeded in most of the cases the targeted \%TD by maximum $5 \%$, revealing that the mould casting technique is quite reliable when the process aims at obtaining a specific density level, where the void volume is entirely consisting of an open porous network. While no change was observed by increasing the annealing temperature from $1500^{\circ} \mathrm{C}$ to $1600^{\circ} \mathrm{C}$, an increase of $2-3 \%$ TD was observed at $1850^{\circ} \mathrm{C}$. Approaching the operating temperatures of ISOL targets, i.e., for the heat treatments of $2 \mathrm{~h}$ and $12 \mathrm{~h}$ at $2200^{\circ} \mathrm{C}$, an overall further increase of $5-10 \%$ TD was observed (within reasonable uncertainty ranges), without any significant difference between the materials annealed for $2 \mathrm{~h}$ and $12 \mathrm{~h}$. The latter finding indicates that a dwell time of $2 \mathrm{~h}$ at $2200^{\circ} \mathrm{C}$ is sufficient to stabilize a slightly densified microstructure, and that the sintering mechanisms driving densification through neck formation and grain boundary diffusion have already resulted in a thermally stable porous material microstructure. Further densification by grain boundary and transgranular diffusion is limited at $2200^{\circ} \mathrm{C}$. This finding, supported by SEM imaging, suggests that the studied materials show potential for the ISOL target application, since they are not only characterised by an open interconnected porosity, but their porous microstructure is stable at the ISOL-relevant operation temperature of $2200^{\circ} \mathrm{C}$ for several hours (at least up to $12 \mathrm{~h}$ ).

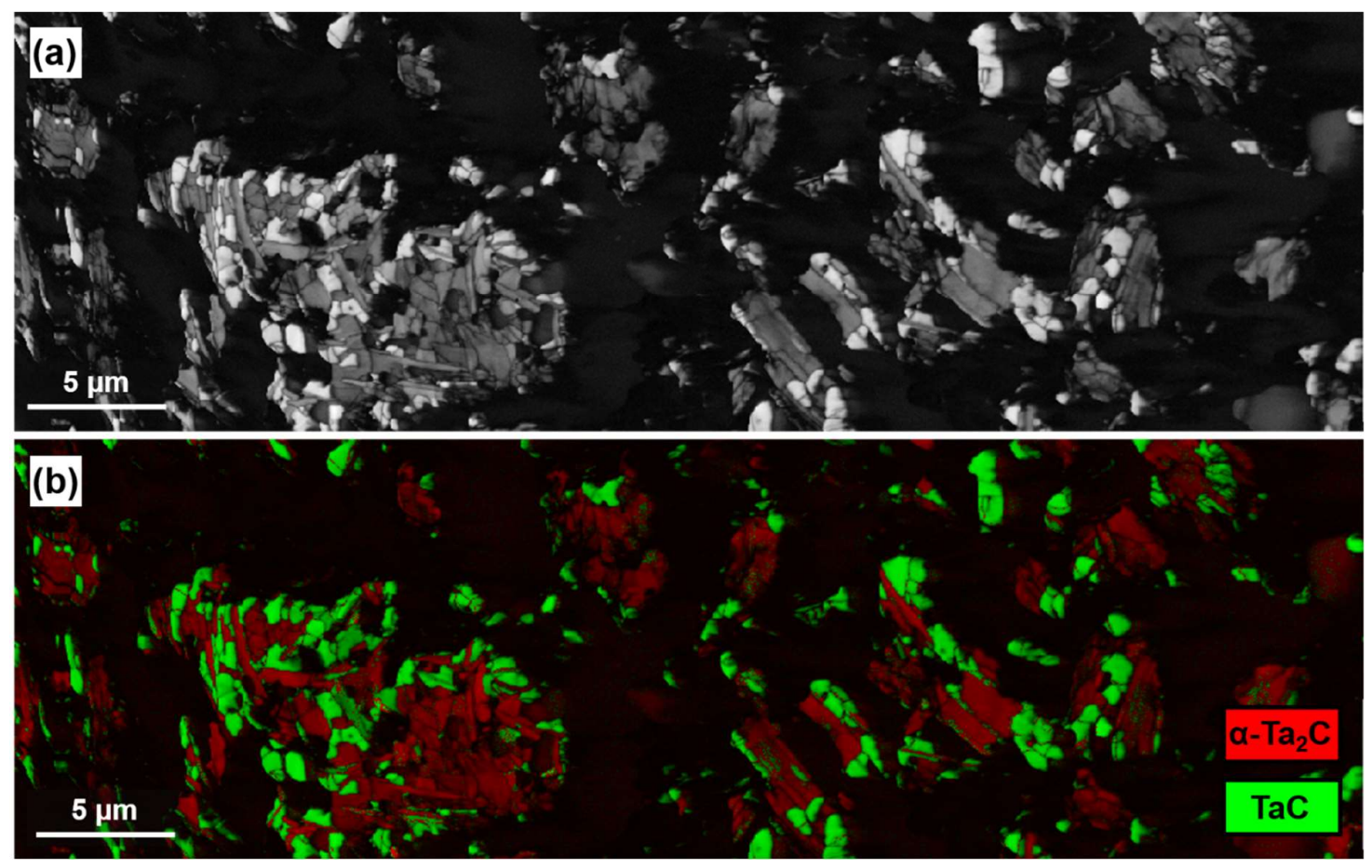

Fig. 7. (a) BSE image and (b) EBSD phase map of TP40 after annealing at $1850^{\circ} \mathrm{C}$ for $2 \mathrm{~h}$. 
The reference TC grades produced from commercial TaC powder and annealed at $1850^{\circ} \mathrm{C}$ for $2 \mathrm{~h}$ and at $2200^{\circ} \mathrm{C}$ for $2 \mathrm{~h}$ and $12 \mathrm{~h}$ were compared with the grades produced from the $\mathrm{Ta}_{4} \mathrm{AlC}_{3}$ MAX phase precursor in terms of obtained density. While the obtained \%TD values of the T50 and TC50 grades coincided, the addition of pore-formers in order to achieve a lower \%TD in the TC grades did not result in the desired density reduction. The reason behind this is the limited ability of the finer $\mathrm{TaC}$ particles to retain the shape of the cavities once the pore-formers evaporated and consolidation occurred at $1850^{\circ} \mathrm{C}$. As a result, the cavities partially collapsed or shrunk, resulting in a final density that did not deviate as much as intended from that of the TC50 grade. Regarding the heat treatments at $2200^{\circ} \mathrm{C}$, a certain degree of densification was observed particularly for the lower density grades, again possibly due to the shrinkage of cavities. Moreover, no further densification of the TC grades was observed when annealing at $2200^{\circ} \mathrm{C}$ was prolonged from $2 \mathrm{~h}$ to $12 \mathrm{~h}$, indicating that pore stabilization occurred in the materials based on commercial TaC powder as well. In general, TC50 showed a more stable porosity at $2200^{\circ} \mathrm{C}$ as compared to $\mathrm{T} 50$.
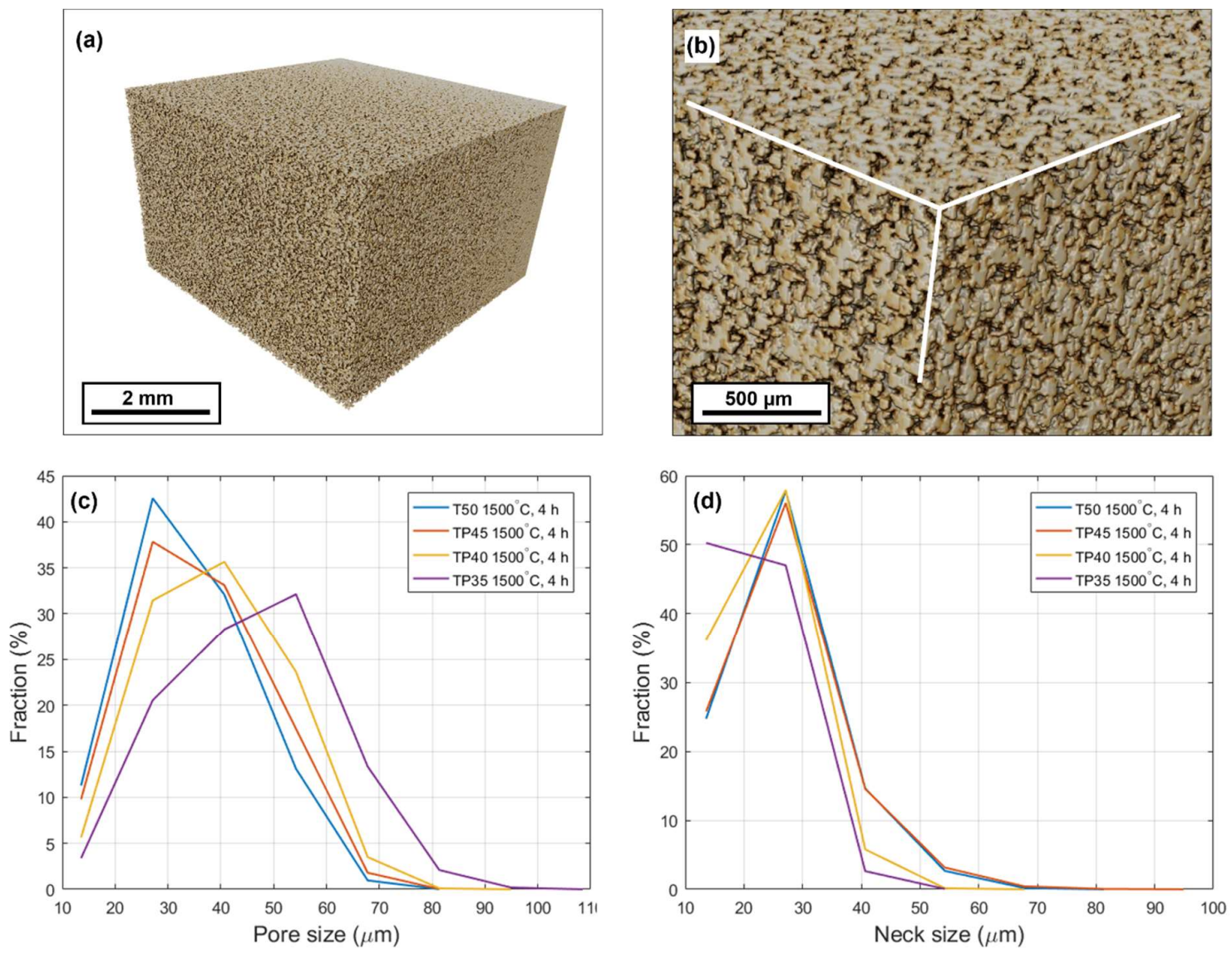

Fig. 8. $\mu \mathrm{CT}$ scan of $\mathrm{T} 50$ annealed at $1500^{\circ} \mathrm{C}$ for $4 \mathrm{~h}$ : (a) overview and (b) microstructural detail. Distribution of pore sizes (c) and neck sizes (d) for the ceramics annealed at $1500^{\circ} \mathrm{C}$ for $4 \mathrm{~h}$.

$\mathrm{XRD}$ analysis of the grades produced from the $\mathrm{Ta}_{4} \mathrm{AlC}_{3} \mathrm{MAX}$ phase precursor and annealed at lower temperatures (i.e., $1500-1850^{\circ} \mathrm{C}$ ) showed the presence of the $\alpha-\mathrm{Ta}_{2} \mathrm{C}$ phase on the disc surface along with cubic $\mathrm{TaC}_{\mathrm{x}}$ (Fig. 2a). It was interesting to confirm the presence of $\alpha-$ 
$\mathrm{Ta}_{2} \mathrm{C}$ in the inner disc regions as well and to study its distribution in the material bulk. Therefore, a metallographic cross-section of TP40 annealed at $1850^{\circ} \mathrm{C}$ for $2 \mathrm{~h}$ was studied by EBSD to map the distribution of the two phases. A BSE image of the mapped region is shown in Fig. $7 \mathrm{a}$, where the black areas correspond to the material porosity, while the EBSD phase map is shown in Fig. $7 b$. The $\alpha-\mathrm{Ta}_{2} \mathrm{C}$ and cubic $\mathrm{TaC}_{\mathrm{x}}$ phases appear distinctly separated in the solid regions of polished material, with a few incidences of grain clusters from the same phase. From a qualitative observation, the grain size appears to be $<5 \mu \mathrm{m}$, seemingly smaller than that of the distinguishable grains (in Fig. $5 e$ and $5 f$ ) in the material heated for $12 \mathrm{~h}$ at $2200^{\circ} \mathrm{C}$. Upon annealing at $1850^{\circ} \mathrm{C}$ in the $\mathrm{W}$ furnace, the presence of the $\alpha-\mathrm{Ta}_{2} \mathrm{C}$ phase may have played a role in the overall thermal stability of the microstructure, pinning the grain boundaries and inhibiting sintering of the cubic $\mathrm{TaC}_{\mathrm{x}}$ phase during annealing in all locations where the two phases were in contact with each other. This effect was possibly lost when a source of extra $\mathrm{C}$ was present in the $\mathrm{C}$ furnace operating at $2200^{\circ} \mathrm{C}$, as the added $\mathrm{C}$ shifted the composition towards a region of the $\mathrm{Ta}-\mathrm{C}$ phase diagram with only cubic $\mathrm{TaC}$, as mentioned earlier.

Portions of the macroporous matrix in T50 were also imaged by $\mu \mathrm{CT}$, as shown in Fig. 8 a and 8b. In the reconstructed images, each pixel corresponds to $6.8 \mu \mathrm{m}$. It is evident from the $\mu \mathrm{CT}$ scans that several microstructural features are smaller than this pixel size. Nevertheless, the reconstructed $\mu \mathrm{CT}$ scans depict the open porous network, allowing an estimation of the pore size distribution and interconnectivity, also showing the consistency of consolidated parts with necks (conjunctions) between particles. The pore sizes and neck sizes determined by the software are presented in Figs. $8 \mathrm{c}$ and $8 \mathrm{~d}$, respectively. Despite the limitations in resolution, one may observe that the pore size distribution shifted towards larger pore size values as the amount of added pore-formers increased, while the neck size distribution of the microporous matrix remained unchanged, since the structure of this matrix remained unaffected by the addition of pore-formers. The herein acquired results suggest that as long as the microstructure can be imaged within the resolution limit of $\sim 10 \mu \mathrm{m}, \mu \mathrm{CT}$ is an appealing non-destructive technique for the characterization of disc-shaped target materials produced for ISOL facilities.

\subsection{Thermal properties}

In order to characterize the thermal properties of the produced porous ceramics, which are very important for the development of an ISOL target, the specific heat capacity, $\mathrm{C}_{\mathrm{p}}$ (in $\mathrm{J} / \mathrm{g} \cdot \mathrm{K}$ ), was measured from $\mathrm{RT}$ to $1000^{\circ} \mathrm{C}$ on all four $\mathrm{Ta}_{4} \mathrm{AlC}_{3} \mathrm{MAX}$ phase-derived grades after annealing at $1500^{\circ} \mathrm{C}$ for $4 \mathrm{~h}$ and at $2200^{\circ} \mathrm{C}$ for $2 \mathrm{~h}$. As may be seen in Fig. 9a, the heat capacity of all grades increased with temperature, as expected. Moreover, the overall specific heat capacity of the as-synthesised $\left(1500^{\circ} \mathrm{C}, 4 \mathrm{~h}\right) \mathrm{T} 50$ grade, which did not have a bimodal pore size distribution due to the fact that no PA pore-formers were added to it, was higher than the specific heat capacity of the TP grades at all temperatures. This could be attributed to the lower amount of heat required to increase the temperature in a unit of mass $(\mathrm{g})$ of the denser T50 (50\%TD) than the less dense (hence, more heat-dissipating) TP45 (45\%TD), TP40 (40\%TD), and TP30 (30\%TD). Another explanation is the presence of unequal residual amount of $\mathrm{Ta}_{4} \mathrm{AlC}_{3} \mathrm{MAX}$ phase between different grades after annealing at $1500^{\circ} \mathrm{C}$ for $4 \mathrm{~h}$. This was directly observed in all grades annealed at $1500^{\circ} \mathrm{C}$ for $4 \mathrm{~h}$, where the pore size in the base microporous matrix was similar. Moreover, the unknown amount of free carbon remaining from minute residues of processing additives (i.e., wax, hydrophobization agent, PA pore-formers) in these materials might have affected the specific heat capacity, accounting partly for the appreciable difference between the $C_{p}$ values of T50 and all TP grades annealed at $1500^{\circ} \mathrm{C}$ 
for $4 \mathrm{~h}$. At the higher annealing temperature of $2200^{\circ} \mathrm{C}$, where all additive and $\mathrm{Ta}_{4} \mathrm{AlC}_{3}$ residues were eliminated and the microporous matrix was slightly densified, the $C_{p}$ values for all grades were comparable and slightly lower. Prior studies have reported RT $C_{p}$ values in the 0.188 $0.19 \mathrm{~J} / \mathrm{g} \cdot \mathrm{K}$ range for cubic $\mathrm{TaC}$, and in the $0.162-0.163 \mathrm{~J} / \mathrm{g} \cdot \mathrm{K}$ range for hexagonal $\alpha-\mathrm{Ta}_{2} \mathrm{C}$ [43]. These $C_{p}$ values are comparable with the values measured for the porous ceramics in this work. The thermal diffusivity measured by the laser flash method is shown in Fig. 9b and the calculated thermal conductivity in Fig. 9c.

As-synthesised $\left(1500^{\circ} \mathrm{C}, 4 \mathrm{~h}\right)$ TP40 and TP35 exhibited a lower thermal conductivity than T50 as a result of the presence of the larger pores associated with the addition of PA pore-formers, which hindered heat transfer within the material volume. Surprisingly, the thermal diffusivity and, by extension, the thermal conductivity (the product of thermal diffusivity, density and specific heat capacity) of as-synthesised $\left(1500^{\circ} \mathrm{C}, 4 \mathrm{~h}\right)$ TP45 were higher than for TP40, TP35 and T50. This finding is currently difficult to explain, but might be associated with the pore interconnectivity in as-synthesised TP45. It is expected that ineffective dispersion of the PA spheres, leading to local agglomeration and/or local absence of pore-formers from certain areas in the volume of the TP45 'batch' might have affected the overall thermal conductivity/diffusivity of this particular porous ceramic grade.
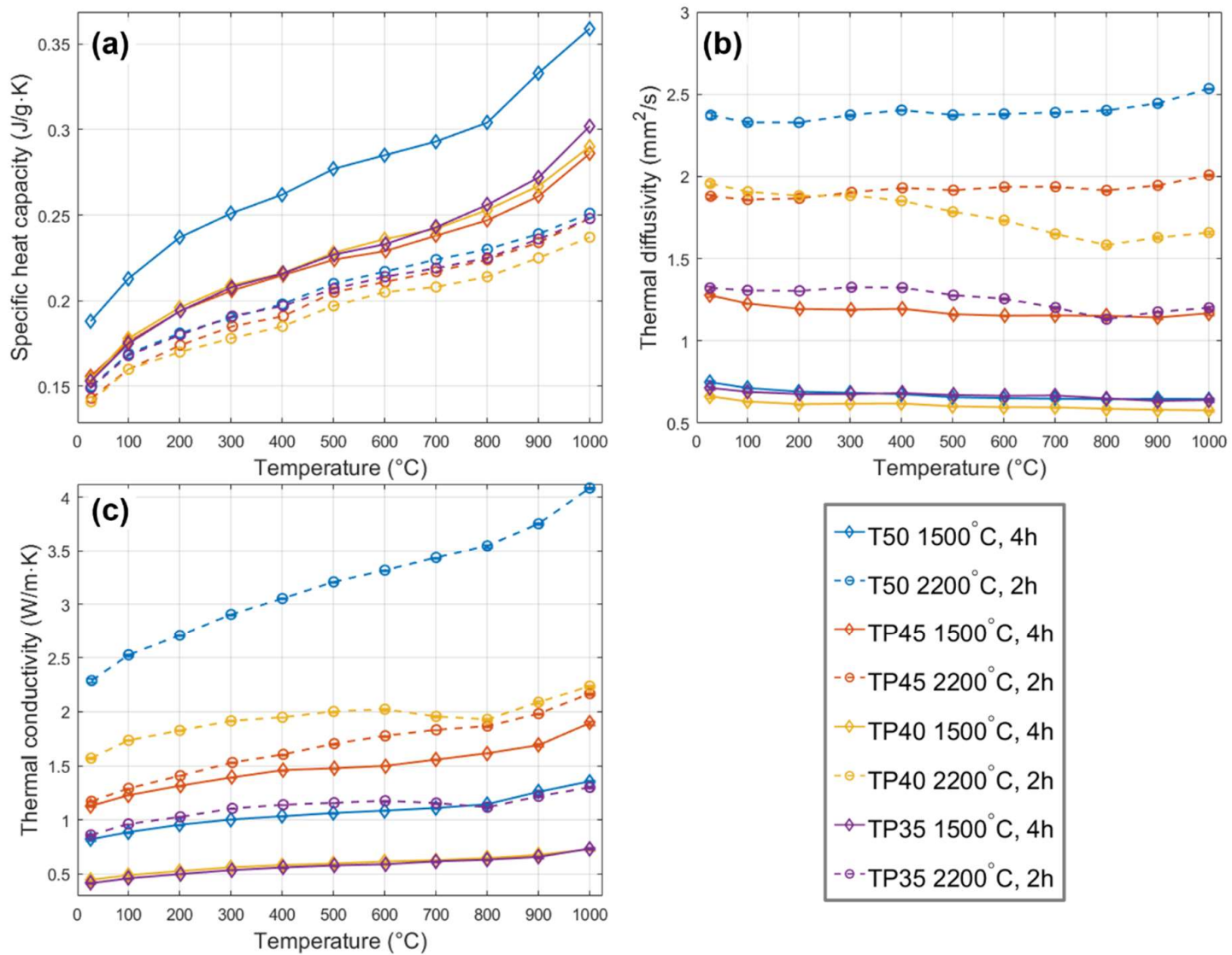

$$
\begin{aligned}
& { }^{\rightarrow} \mathrm{T} 501500^{\circ} \mathrm{C}, 4 \mathrm{~h} \\
& \text { - }- \text {-T50 } 2200^{\circ} \mathrm{C}, 2 \mathrm{~h} \\
& \rightarrow \text { TP45 } 1500^{\circ} \mathrm{C}, 4 \mathrm{~h} \\
& \text { - } \theta-T P 452200^{\circ} \mathrm{C}, 2 \mathrm{~h} \\
& \checkmark \text { TP40 } 1500^{\circ} \mathrm{C}, 4 \mathrm{~h} \\
& \text { - } \theta \text {-TP40 } 2200^{\circ} \mathrm{C}, 2 \mathrm{~h} \\
& \rightarrow \text { TP35 } 1500^{\circ} \mathrm{C}, 4 \mathrm{~h} \\
& \text { - } \theta \text {-TP35 } 2200^{\circ} \mathrm{C}, 2 \mathrm{~h}
\end{aligned}
$$

Fig. 9. (a) Specific heat capacity, (b) thermal diffusivity, and (c) thermal conductivity of the $\mathrm{Ta}_{4} \mathrm{AlC}_{3} \mathrm{MAX}$ phase-derived porous ceramic grades after different heat treatments. 
As result of annealing at $2200^{\circ} \mathrm{C}$ for $2 \mathrm{~h}$, the thermal conductivity of all $\mathrm{Ta}_{4} \mathrm{AlC}_{3} \mathrm{MAX}$ phasederived grades increased because of the limited high-temperature densification of the porous microstructure, ensuring better heat conduction overall. This effect was particularly important for the T50 grade, where the absence of a bimodal pore distribution (no added spherical PA pore-formers) yielded a thermal conductivity of $4 \mathrm{~W} / \mathrm{m} \cdot \mathrm{K}$ at $1000^{\circ} \mathrm{C}$. The apparent inconsistency in the evolution of the thermal conductivity values with increasing fraction of pore formers might again be associated with the batch-specific large pore interconnectivity, as the dispersion of PA pore-formers might have fluctuated slightly from batch to batch. Moreover, the standardized LFA sample thickness of $\sim 2 \mathrm{~mm}$ was not sufficient to offer a statistically relevant average number of cavities in the pathway of the heat pulse. The large cavities introduced by the PA pore-formers had a maximum diameter of $\sim 100 \mu \mathrm{m}$, which was only $5 \%$ of the sample thickness. Despite that fact, these measurements gave a good indication of the thermal conductivity variation in these porous ceramics and its evolution after testing at ISOLrelevant operation temperatures. These measurements are useful for the thermal modelling of a candidate ISOL target, but extrapolation at temperatures well above $1000^{\circ} \mathrm{C}$ is necessary. The RT thermal conductivity of dense cubic TaC has been reported to be in the $10-20 \mathrm{~W} / \mathrm{m} \cdot \mathrm{K}$ range, increasing up to $55 \mathrm{~W} / \mathrm{m} \cdot \mathrm{K}$ at $1000^{\circ} \mathrm{C}$, while the same property for dense $\alpha-\mathrm{Ta}_{2} \mathrm{C}$ has been reported to be in the $20-40 \mathrm{~W} / \mathrm{m} \cdot \mathrm{K}$ range [43]. The comparison of existing data with the herein determined thermal conductivity data provides a measure of the effect of porosity on the overall decrease in thermal conductivity of porous $\mathrm{TaC}_{\mathrm{x}}$ ceramics.

\section{Conclusions and outlook}

A feedstock of wax and $\mathrm{Ta}_{4} \mathrm{AlC}_{3} \mathrm{MAX}$ phase powder with and without additional spherical polyamide (PA) pore-formers was moulded into 'green' discs that underwent wax debinding and pore-former pyrolysis in $\mathrm{Ar}$, followed by vacuum annealing at $1500^{\circ} \mathrm{C}$ for $4 \mathrm{~h}$ that aimed at dealumination of the $\mathrm{Ta}_{4} \mathrm{AlC}_{3} \mathrm{MAX}$ phase and overall partial densification. The produced porous ceramics were a biphasic $\mathrm{Ta}_{2} \mathrm{C}-\mathrm{TaC}_{\mathrm{x}}$ mixture with $\mathrm{Ta}_{4} \mathrm{AlC}_{3}$ residues below $1850^{\circ} \mathrm{C}$, and (primarily) single-phase $\mathrm{TaC}_{x}$ with residues of $\mathrm{Ta}_{2} \mathrm{C}$ at $2200^{\circ} \mathrm{C}$. The final densities varied in the $36-53 \%$ TD range, depending on the amount of added PA pore-formers. These ceramics were characterised by bimodal pore size distributions and showed porosity on two distinct scales, as they consisted of a matrix with fine interconnected pores (average pore size $\approx 1 \mu \mathrm{m}$ ) and a dispersion of much larger spherical $(\leq 100 \mu \mathrm{m})$ pores. The same processing route was followed to produce porous ceramics from commercial TaC powders (TC grades); these ceramics had a larger SSA due to a finer porous matrix, but were not characterised by a bimodal pore size distribution as result of the addition of sacrificial pore-formers.

The main conclusions of this work, which aimed at the development of novel porous $\mathrm{TaC}_{\mathrm{x}} \mathrm{ISOL}$ target materials, may be summarized as follows:

1. The highly porous grades derived from $\mathrm{Ta}_{4} \mathrm{AlC}_{3} \mathrm{MAX}$ phase powders mixed with the highest amount of PA pore-formers (30 vol\%) proved to be as thermally stable as the same grades with less pore-formers. The inconsistent final density of the TC grades produced from commercial $\mathrm{TaC}$ powders suggests that some of the cavities created by the PA pore-formers collapsed in these materials.

2. All porous $\operatorname{TaC}_{x}$ ceramics exhibited very satisfactory thermal stability at ISOL-relevant conditions, i.e., at $2200^{\circ} \mathrm{C}$ for up to $12 \mathrm{~h}$. The overall microstructural stability and limited 
evidence of high-temperature consolidation is encouraging for their potential use as candidate ISOL target materials with long-term intended operation.

3. Two porous material characterisation techniques proved valuable quality control tools for ISOL target materials. First, mercury intrusion porosimetry (MIP) can assess the interconnectivity of the pore network and provide feedback on how best to exploit different pore size distributions to evacuate the evaporating species during target service. Moreover, $\mu \mathrm{CT}$ is a non-destructive technique that may be used to accurately image the porous material microstructure.

In principle, the presence of larger cavities within a matrix of fine porosity is expected to decrease the number of collisions of the effusing isotopes after their release from the solid target material, while the numerous channels connecting the larger cavities should provide ample pathways for faster isotope extraction. A possible future development that seems worthwhile exploring could consider using highly directional pore channels based on PA fibres or scaffold-like sacrificial templates to improve the effusion of produced isotopes.

\section{Acknowledgements}

M. Griseri thanks SCK CEN for his PhD fellowship through the ISOL@MYRRHA project. Additional acknowledgments are due to the technical and academic staff of the Department of Materials Engineering (MTM) of KU Leuven, the scientific and technical staff of the Proton Target Research (PTR) group at SCK CEN, and the Department of Materials Science and Engineering at Friedrich-Alexander-Universität Erlangen-Nürnberg for practical help and support. Special thanks are also due to Dr. B. Tunca for her help with the EBSD measurements. 


\section{Bibliography}

[1] M. Borge, Y. Kadi, ISOLDE at CERN, Nucl. Phys. News. 26 (2016) 6-13.

[2] R. dos Santos Augusto, L. Buehler, Z. Lawson, S. Marzari, M. Stachura, T. Stora, CERN-MEDICIS (Medical Isotopes Collected from ISOLDE): A New Facility, Appl. Sci. 4 (2014) 265-281.

[3] G.J. Beyer, E. Hagebø, A.F. Novgorodov, H.L. Ravn, The role of diffusion in ISOL targets for the production of radioactive ion beams, Nucl. Instruments Methods Phys. Res. Sect. B Beam Interact. with Mater. Atoms. 204 (2003) 225-234.

[4] M. Dombsky, P. Kunz, ISAC targets, Hyperfine Interact. 225 (2014) 17-23.

[5] J.P. Ramos, Titanium carbide-carbon porous nanocomposite materials for radioactive ion beam production: processing, sintering and isotope release properties, EPFL, PhD Thesis, 2017.

[6] J.P. Ramos, T. Stora, A.M.R. Senos, P. Bowen, Thermal stability of nanometric TiCcarbon composites: effects of carbon allotropes and Zr milling impurities, J. Eur. Ceram. Soc. 38 (2018) 4882-4891.

[7] A. Gottberg, Target materials for exotic ISOL beams, Nucl. Instruments Methods Phys. Res. Sect. B Beam Interact. with Mater. Atoms. 376 (2016) 8-15.

[8] J.P. Ramos, Thick solid targets for the production and online release of radioisotopes: The importance of the material characteristics - A review, Nucl. Instruments Methods Phys. Res. Sect. B Beam Interact. with Mater. Atoms. (2019).

[9] C. Müller, C. Vermeulen, U. Köster, K. Johnston, A. Türler, R. Schibli, N.P. van der Meulen, Alpha-PET with terbium-149: evidence and perspectives for radiotheragnostics, Radiopharm. Chem. (2016).

[10] G.J. Beyer, J.J. Čomor, M. Daković, D. Soloviev, C. Tamburella, E. Hagebø, B. Allan, S.N. Dmitriev, N.G. Zaitseva, G.Y. Starodub, L.G. Molokanova, S. Vranješ, M. Miederer, Production routes of the alpha emitting ${ }^{149} \mathrm{~Tb}$ for medical application, Radiochim. Acta. 90 (2002) 247-252.

[11] T. Bjørnstad, E. Hagebø, P. Hoff, O.C. Jonsson, E. Kugler, H.L. Ravn, S. Sundell, B. Vosicki, Recent development of high-temperature metal targets for ISOLDE, Nucl. Instruments Methods Phys. Res. Sect. B Beam Interact. with Mater. Atoms. 26 (1987) 174-182.

[12] H.L. Ravn, T. Bjørnstad, P. Hoff, O.C. Jonsson, E. Kugler, S. Sundell, B. Vosički, Use of refractory oxides, carbides and borides as targets for on-line mass separation, Nucl. Instruments Methods Phys. Res. Sect. B Beam Interact. with Mater. Atoms. 26 (1987) 183-189.

[13] J.P. Ramos, A.M.R. Senos, T. Stora, C.M. Fernandes, P. Bowen, Development of a processing route for carbon allotrope-based TiC porous nanocomposites, J. Eur. Ceram. Soc. 37 (2017) 3899-3908.

[14] S. Fernandes, H. Vogel, T. Stora, Submicro and Nano Structured Porous Materials for the Production of High-Intensity Exotic Radioactive Ion Beams, (2010).

[15] J. Wong, Development of nanofibrous target materials for short-lived isotope production, (2018).

[16] P. Van Duppen, ISOL at MYRRHA: An application of the MYRRHA accelerator for nuclear physics, in: Int. Top. Meet. Nucl. Res. Appl. Util. Accel., 2009.

[17] P. Dieter and P. Schuurmans., ISOL@MYRRHA, An On-Line Isotope Separator coupled to the MYRHHA Proton Accelerator, 2009. 
[18] SCK-CEN, ISOL@MYRRHA: Fundamental physics at MYRRHA, (n.d.). https://isolmyrrha.sckcen.be/.

[19] B.C. Mutsuddy, R.G. Ford, Ceramics Injection Molding, Springer US, 1994.

[20] T. Moritz, R. Lenk, Ceramic Injection Moulding: A Review of Developments in Production Technology, Materials and Applications, Powder Inject. Mould. Int. 3 (2009) 23-34.

[21] M. Götz, T. Fey, P. Greil, Vibration Assisted Self $\square$ Assembly Processing of Ceramic $\square$ Based Composites with Modular Meta $\square$ Structure, J. Am. Ceram. Soc. 95 (2012).

[22] T. Fey, M. Götz, P. Greil, Photoelastic Imaging of Residual Stress Distribution in Epoxy Interface Layers of Ceramics with Periodic Building Block Structure, Adv. Eng. Mater. 15 (2013).

[23] J. Biggemann, B. Diepold, M. Pezoldt, M. Stumpf, P. Greil, T. Fey, Automated 3D assembly of periodic alumina $\square$ epoxy composite structures, J. Am. Ceram. Soc. 101 (2018) 3864-3873.

[24] J. Biggemann, M. Pezoldt, M. Stumpf, P. Greil, T. Fey, Modular ceramic scaffolds for individual implants, Acta Biomater. 80 (2018) 390-400.

[25] J. Biggemann, P. Hoffmann, I. Hristov, S. Simon, P. Müller, T. Fey, Injection Molding of 3-3 Hydroxyapatite Composites, Materials (Basel). 13 (2020) 1907.

[26] J. Biggemann, P. Müller, D. Köllner, S. Simon, P. Hoffmann, P. Heik, J.H. Lee, T. Fey, Hierarchical Surface Texturing of Hydroxyapatite Ceramics: Influence on the Adhesive Bonding Strength of Polymeric Polycaprolactone., J. Funct. Biomater. 11 (2020).

[27] M. Griseri, B. Tunca, T. Lapauw, S. Huang, L. Popescu, M.W. Barsoum, K. Lambrinou, J. Vleugels, Synthesis, properties and thermal decomposition of the $\mathrm{Ta}_{4} \mathrm{AlC}_{3} \mathrm{MAX}$ phase, J. Eur. Ceram. Soc. 39 (2019) 2973-2981.

[28] A.L. Bowman, The Variation of Lattice Parameter with Carbon Content of Tantalum Carbide , J. Phys. Chem. 65 (1961) 1596-1598.

[29] F. Shojai, A.B.. Pettersson, T. Mäntylä, J.. Rosenholm, Electrostatic and electrosteric stabilization of aqueous slips of $3 Y-\mathrm{ZrO}_{2}$ powder, J. Eur. Ceram. Soc. 20 (2000) 277283.

[30] H. Sarraf, J. Havrda, Rheological behavior of concentrated alumina suspension: Effect of electrosteric stabilization, Ceram. - Silikaty. 51 (2007) 147-152.

[31] L. Lutterotti, S. Matthies, H.R. Wenk, MAUD: a friendly Java program for material analysis using diffraction, IUCr Newsl. CPD. 21 (1999).

[32] ASTM International, ASTM B962-17, Standard Test Methods for Density of Compacted or Sintered Powder Metallurgy (PM) Products Using Archimedes' Principle, (2017).

[33] ASTM International, ASTM D4404-18, Standard Test Method for Determination of Pore Volume and Pore Volume Distribution of Soil and Rock by Mercury Intrusion Porosimetry, (2018).

[34] P. Klobes, K. Meyer, R.G. Munro, Porosity and specific surface area measurements for solid materials., Dept. of Commerce, Technology Administration, National Institute of Standards and Technology., Gaithersburg, Md.: U.S., 2006.

[35] H.M. Rootare, C.F. Prenzlow, Surface areas from mercury porosimeter measurements, J. Phys. Chem. 71 (1967) 2733-2736.

[36] E.W. Washburn, Note on a Method of Determining the Distribution of Pore Sizes in a Porous Material, Proc. Natl. Acad. Sci. U. S. A. 7 (1921) 115-116.

[37] A.I. Gusev, A.S. Kurlov, V.N. Lipatnikov, Atomic and vacancy ordering in carbide $\zeta-$ 
$\mathrm{Ta}_{4} \mathrm{C}_{3-\mathrm{x}}(0.28 \leqslant \mathrm{x} \leqslant 0.40)$ and phase equilibria in the Ta-C system, J. Solid State Chem. 180 (2007) 3234-3246.

[38] M.W. Barsoum, MAX Phases, Properties of Machinable Ternary Carbides and Nitrides, Wiley-VCH, 2013.

[39] A.L. Bowman, T.C. Wallace, J.L. Yarnell, R.G. Wenzel, E.K. Storms, The crystal structures of $\mathrm{V}_{2} \mathrm{C}$ and $\mathrm{Ta}_{2} \mathrm{C}$, Acta Crystallogr. 19 (1965) 6-9.

[40] S. Corradetti, L. Biasetto, M.D.M. Innocentini, S. Carturan, P. Colombo, A. Andrighetto, Use of polymeric fibers to increase gas permeability of lanthanum carbide based targets for nuclear physics applications, Ceram. Int. 42 (2016) 17764-17772.

[41] L. Biasetto, M.D.M. Innocentini, W.S. Chacon, S. Corradetti, S. Carturan, P. Colombo, A. Andrighetto, Gas permeability of lanthanum oxycarbide targets for the SPES project, J. Nucl. Mater. 440 (2013) 70-80.

[42] S. Corradetti, C. Anelli, L. Biasetto, M.D.M. Innocentini, S. Carturan, P. Colombo, A. Andrighetto, Effect of sacrificial fiber length on gas permeability of lanthanum carbide, Ceram. Int. 44 (2018) 4483-4486.

[43] I.L. Shabalin, Ultra-High Temperature Materials II, Springer, 2019. 


\section{Supplementary material}

\subsection{Additional SEM micrographs}

This section provides a complete overview of the microstructural evolution of annealed porous $\mathrm{TaC}_{x}$ materials by presenting SEM micrographs of fracture material surfaces. The mouldcasted $\mathrm{TaC}_{\mathrm{x}}$ had a highly porous (open porosity) microstructure after all annealing treatments, as shown at different scales in Fig. 5. The microporous matrix originates from local necking between powder particles at high temperatures, due to the merging of smaller pores into larger stable structures without any visible major densification effects. Fig. S1 shows a greater detail of the microstructure of the T50 grade after the various heat treatments. The SE images of fracture surfaces in Fig. S2 at a lower magnification show the bimodal pore microstructure created in the TP45, TP40 and TP35 grades from the addition of PA spheres to the master feedstock. These images are compared to the T50 grade that has no bimodal pore structure. The large cavities have a consistent size between 10-70 $\mu \mathrm{m}$, which do not appear to be altered by annealing. A similar overview is provided in Fig. S3 for the TC grades that were produced using commercial TaC powders.
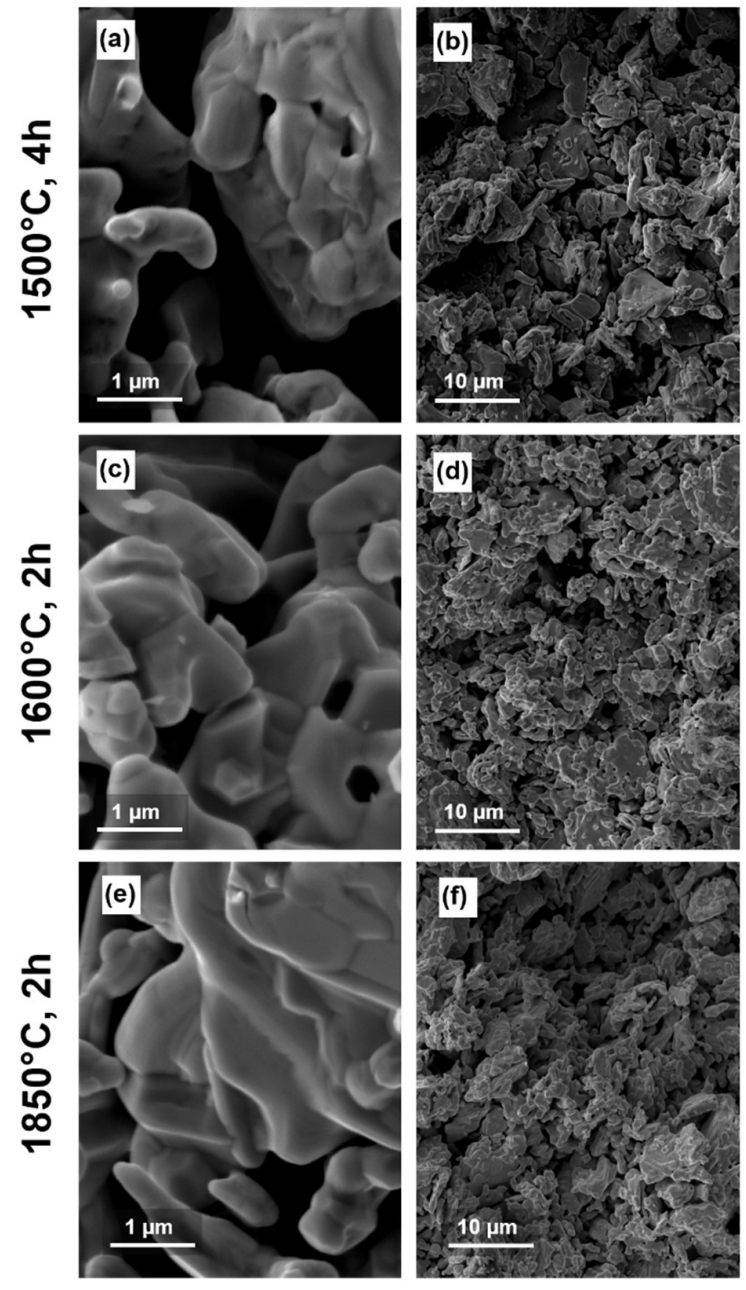
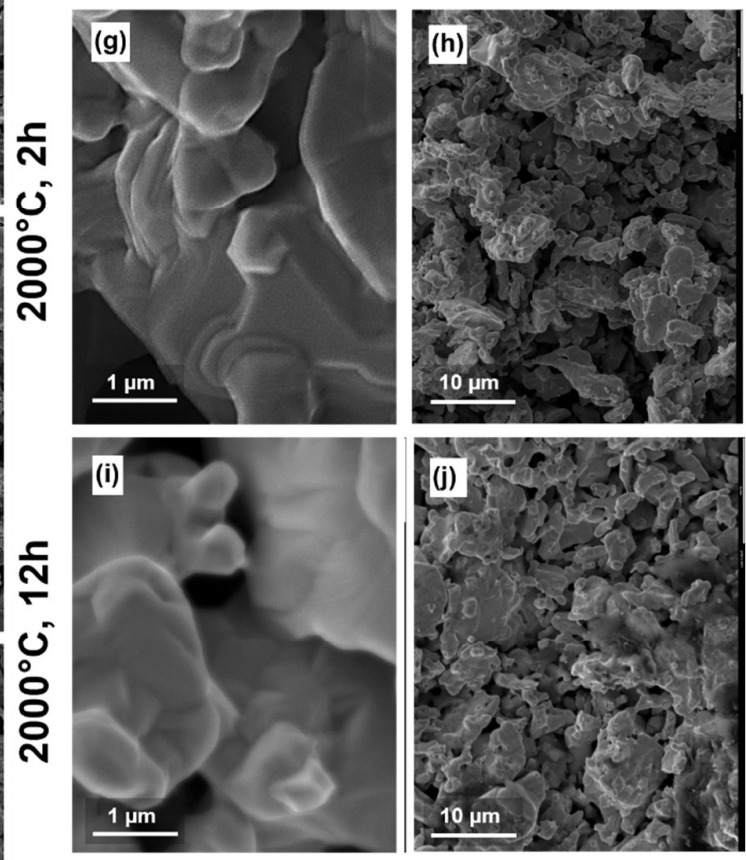

Fig. S1. SEM images of the microporous matrix after different heat treatments in T50, pairs at different magnifications. 

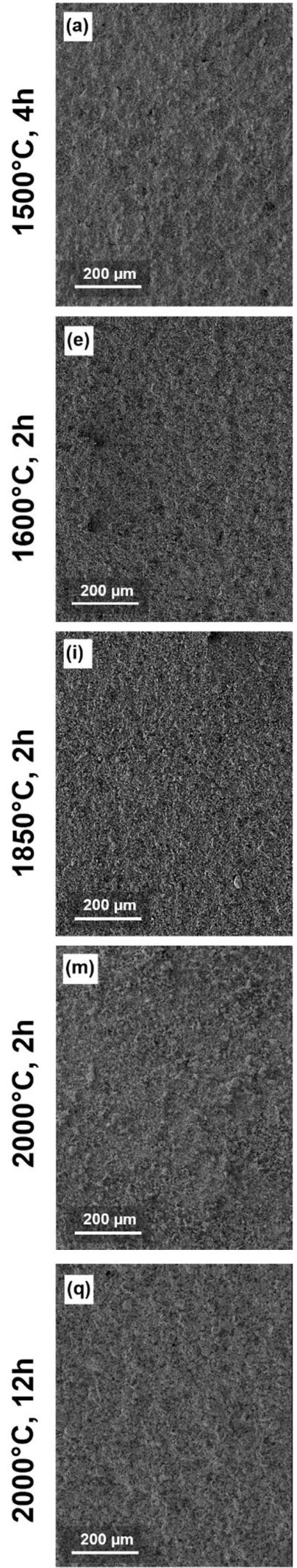

TP45

TP40
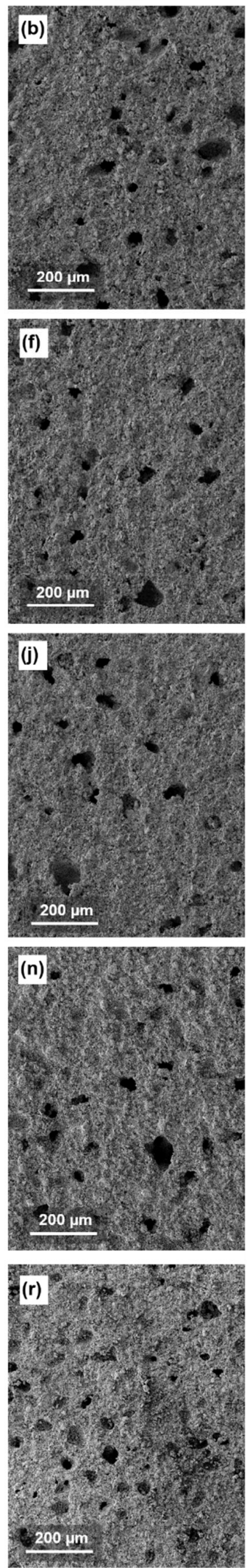
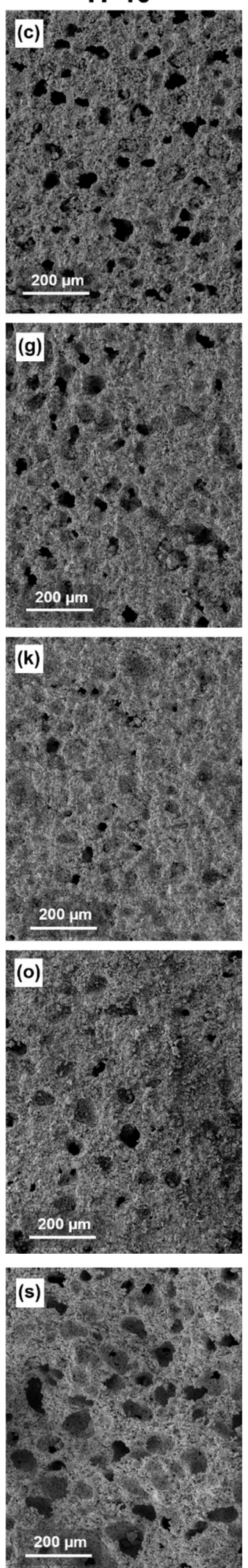

TP35
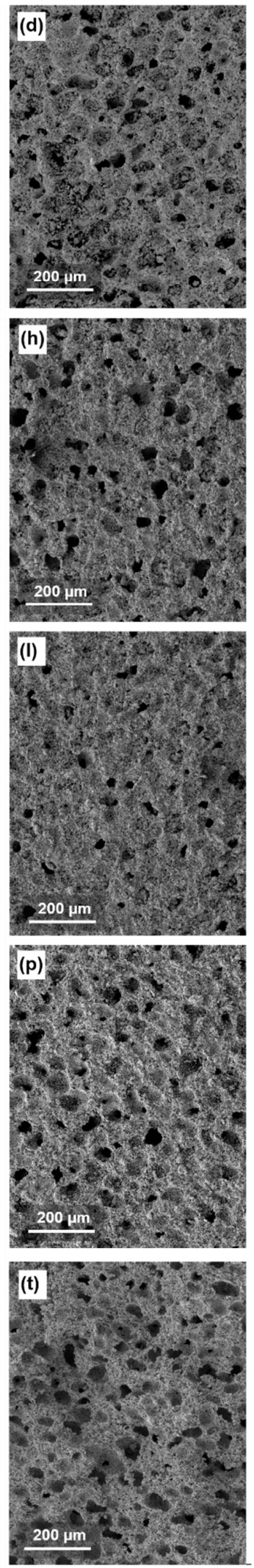

Fig. S2. SE images of the fracture surfaces of TP grades after different heat treatments. 

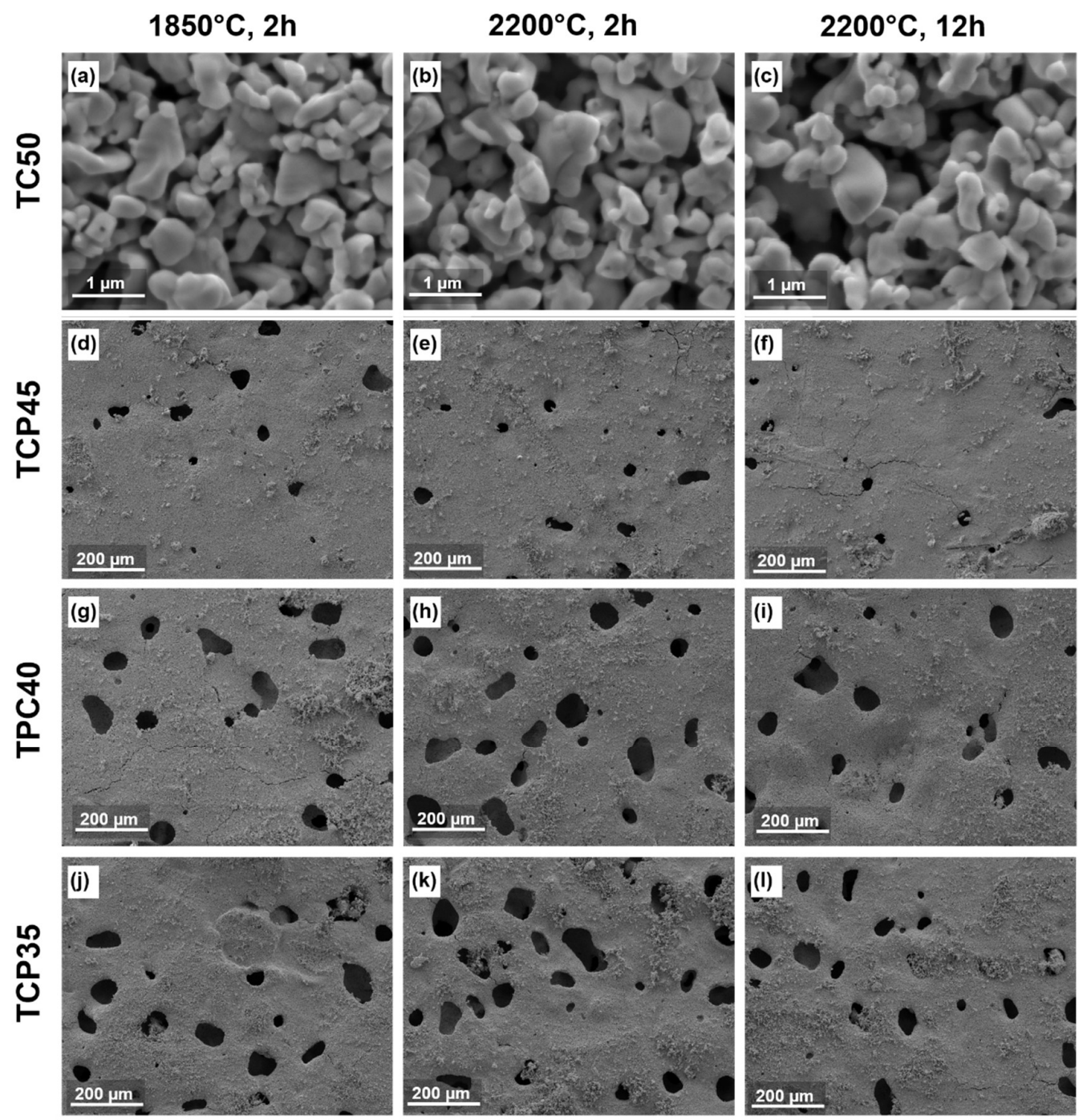

Fig. S3. SE images of the fracture surfaces of TC grades after different heat treatments. 


\subsection{Additional $\mu \mathrm{CT}$ scans}

The $\mu \mathrm{CT}$ scans of all TP grades annealed at $1500^{\circ} \mathrm{C}$ for $4 \mathrm{~h}$ are shown in Fig. S4 at the lowest magnification, and in Fig. S5 at $4 \times$ higher magnification. The lower magnification scans show how the base porous network (matrix) appears homogeneous across the probed volume. The higher magnification scans show more details, with particle necks in the solid structure, and a porous network.
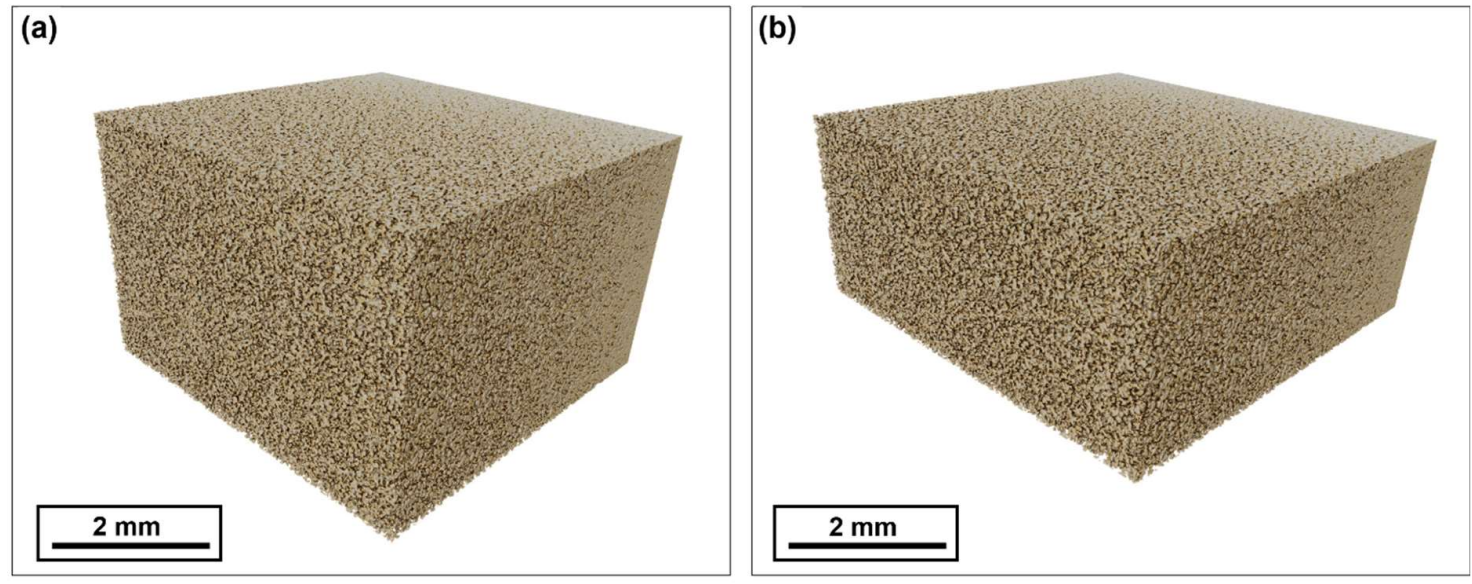

(c)

(d)
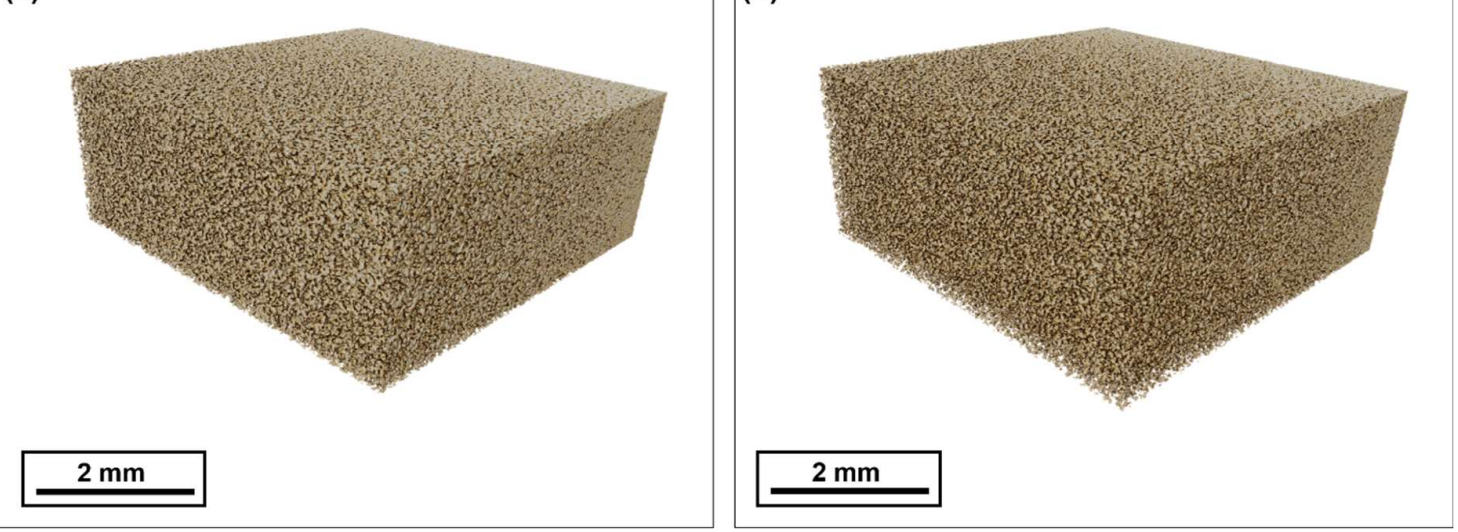

Fig. S4. $\mu$ CT scans of T50 (a), TP45 (b), TP40 (c), TP35 (d) after annealing at $1500^{\circ} \mathrm{C}$ for $2 \mathrm{~h}$. 

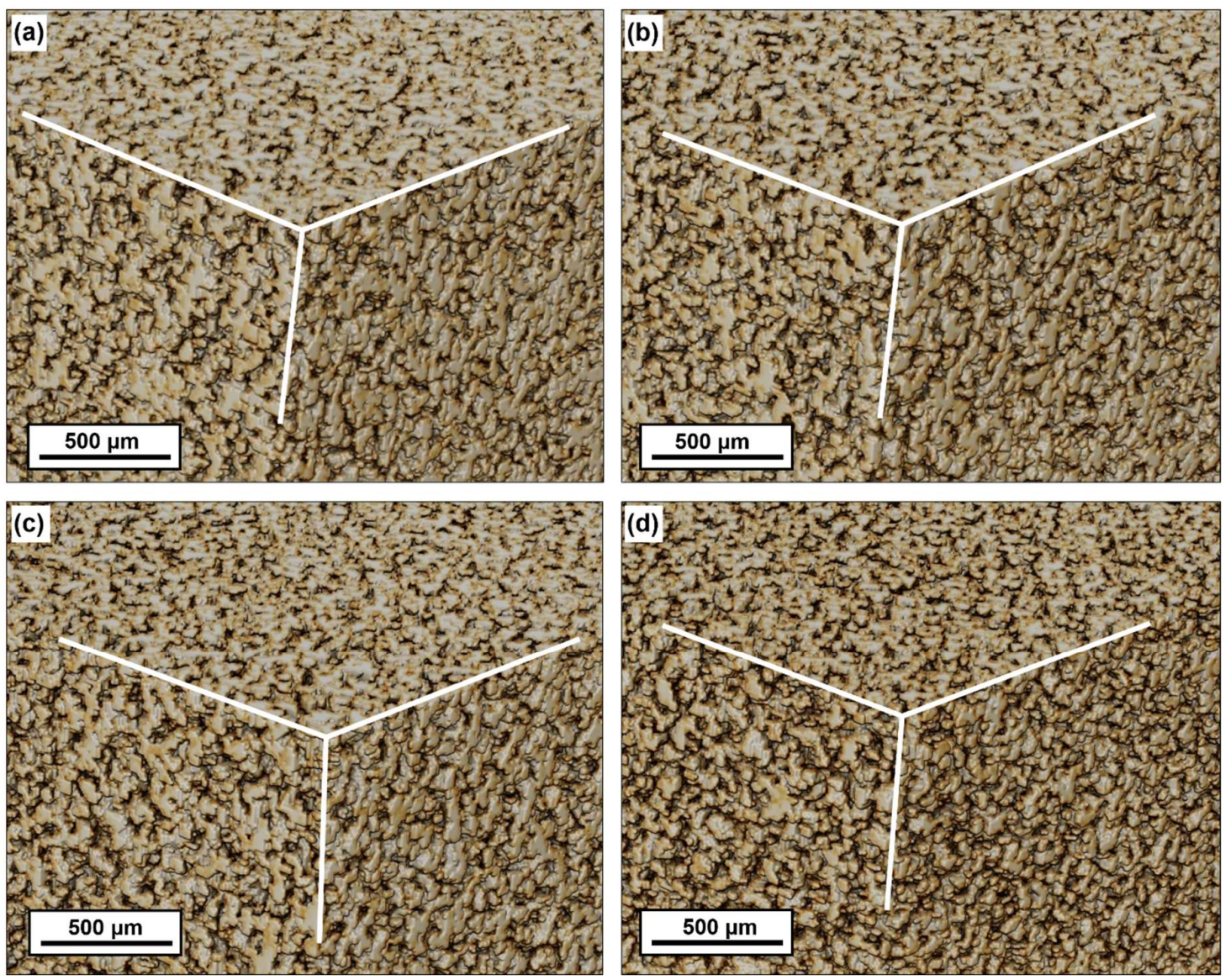

Fig. S5. $\mu$ CT scans of T50 (a), TP45 (b), TP40 (c), TP35 (d), after annealing at $1500^{\circ} \mathrm{C}$ for 2 h. Detail at $4 \times$ higher magnification than the scans shown in Fig. S4.

\subsection{Calculation of the SSA by AutoPore IV 9500}

The software AutoPore IV 9500 determines the pore wall surface, which is equated to the total area $A$ of a sample of mass $m$ (where the specific surface area can be defined as $S S A=A / m$ ), by means of the work spent to introduce the $\mathrm{Hg}$ and cover the pore surface. The reversible work $d W$ required to immerse an area $d A$ of a non-wetting surface is [35]:

$d W=\gamma \cos \theta d A$

where $\gamma$ is the surface tension of $\mathrm{Hg}$, and $\theta$ its contact angle with the surface. When analysing powders, and in the present case where the material consists of a pre-sintered powder agglomerate, it is assumed $\theta=130^{\circ}$. The work is spent when an external pressure $P$ forces a $\mathrm{Hg}$ volume $d V$ into the porous structure, therefore:

$-P d V=\gamma \cos \theta d A$

Assuming that the surface tension $\gamma$ and the contact angle $\theta$ are constant with pressure, one can integrate as follows:

$A=-\frac{\int P d V}{\gamma \cos \theta}$ 
which, translated into discrete volume intrusion steps $\Delta V$, gives the corresponding increments of pore surface area $\Delta A$ :

$\sum \Delta A=-\frac{\sum P \Delta V}{\gamma \cos \theta}=\mathrm{A}=S S A \cdot m$

The same result can be obtained by deriving the pore wall surface area from geometric relationships [36]. The relationship that describes the penetration of $\mathrm{Hg}$ into a cylindrical pore of diameter $\mathrm{D}$ derived from equating the applied pressure to the resisting surface tension is:

$P D=-4 \gamma \cos \theta$

The relationship between wall area, diameter and volume for a cylinder is:

$A=\frac{4 V}{D}$

Combining the two relations, one obtains:

$A=\frac{-P V}{\gamma \cos \theta}$

which can be seen as a sum of increments of covered area $\Delta A$ and intruded volume $\Delta V$ :

$\sum \Delta A=-\frac{\sum P \Delta V}{\gamma \cos \theta}=\mathrm{A}=S S A \cdot m$

During an exploratory study performed on mould-casted $\mathrm{TaC}_{\mathrm{x}}$, a few BET $\mathrm{N}_{2}$ adsorption measurements were also performed to measure the SSA. This method is generally considered more accurate for the SSA estimation, and the obtained result was $0.43(36) \mathrm{m}^{2} / \mathrm{g}$ after consolidation, and $0.266(9) \mathrm{m}^{2} / \mathrm{g}$ after annealing at $1900^{\circ} \mathrm{C}$ for $4 \mathrm{~h}$. Due to the fact that $\mathrm{N}_{2}$ adsorption required large amounts of material and the destruction of each disc, it was decided to not employ this technique for the systematic characterization of the pore size distribution. However, this preliminary $\mathrm{N}_{2}$ adsorption study confirmed that before and after hightemperature annealing, the SSA decreased by roughly $50 \%$. This finding, together with the matching, in order of magnitude, of the SSA values, served as parameter to confirm that MIP is useful for the SSA estimation and its relative change after annealing.

\subsection{Determination of density and porosity}

A method to determine density and porosity of the porous materials was specially devised; in this method, all porosity was assumed to be open and interconnected, an assumption supported by SEM analysis. The method combined the Archimedes' method, which determines the volume of a material body $\left(V_{\text {material }}\right)$ by its buoyancy force in a fluid, with soaking the material in a liquid with low surface tension: in this case, ethanol $(22.39 \mathrm{mN} / \mathrm{m}$ in air at $20^{\circ} \mathrm{C}$ ). The established experimental process can be summarized in the following steps:

- The sample was weighed dry: $m_{d r y}$;

- The sample was placed inside a desiccator, which was closed and evacuated;

- Ethanol was poured in the container with the sample, covering it completely;

- Vacuuming was kept until all bubbling from the surface of the sample disappeared;

- A constant negative pressure of -0.85 bar was reached;

- The samples were removed and quickly patted dry on an ethanol-soaked paper and weighed: $m_{\text {wet, out }}$;

- The sample was immersed again in ethanol in an immersed basket, which allowed the determination of the buoyancy force: $m_{w e t, i n}$.

Given the following relations: 
$m_{\text {dry }}=\rho_{\text {theoretica }} V_{\text {material }}$

$m_{\text {wet }, \text { out }}=m_{\text {dry }}+\rho_{\text {ethan }} \quad V_{\text {open pores }} \rightarrow V_{\text {open pores }}=\frac{\left(m_{\text {wet }, \text { out }}-m_{\text {dry }}\right)}{\rho_{\text {ethanol }}}$

the measured immersed mass was corrected by the buoyancy force:

$m_{\text {wet }, \text { in }}=m_{\text {dry }}-\rho_{\text {ethan }}\left(V_{\text {material }}+V_{\text {closed pores }}\right)$

$\left(V_{\text {material }}+V_{\text {closed pores }}\right)=\left(m_{\text {dry }}-m_{\text {wet,in }}\right) / \rho_{\text {et }}$

$V_{\text {apparent }}=\left(V_{\text {material }}+V_{\text {closed pores }}+V_{\text {open pores }}\right)$

and the apparent (or geometrical) density was determined:

$\rho_{\text {apparent }}=m_{\text {dry }} / V_{\text {apparent }}$

The method was used extensively and repeatedly on the same samples after evaporation of the soaked ethanol in a furnace at $90^{\circ} \mathrm{C}$. The uncertainty on the determined average values was associated with the standard deviations obtained from the different measurements.

\subsection{Thermal test bench - "C furnace"}

The thermal test bench was used to assess the performance of porous $\mathrm{TaC}_{\mathrm{x}}$ under conditions similar to the service conditions of a real ISOL target, i.e., high temperatures, vacuum, prolonged periods of time (hours to several days). The goal was to assess whether and to which extent the microstructure of the porous ceramics was affected by dwelling at high temperatures. The ideal annealing temperatures for such experiments is $2200^{\circ} \mathrm{C}$. The thermal test bench accommodates discs of $\varnothing 1.5 \mathrm{~cm}$, which is the recommended by TRIUMF sample size for off-line release tests at the ISAC facility.
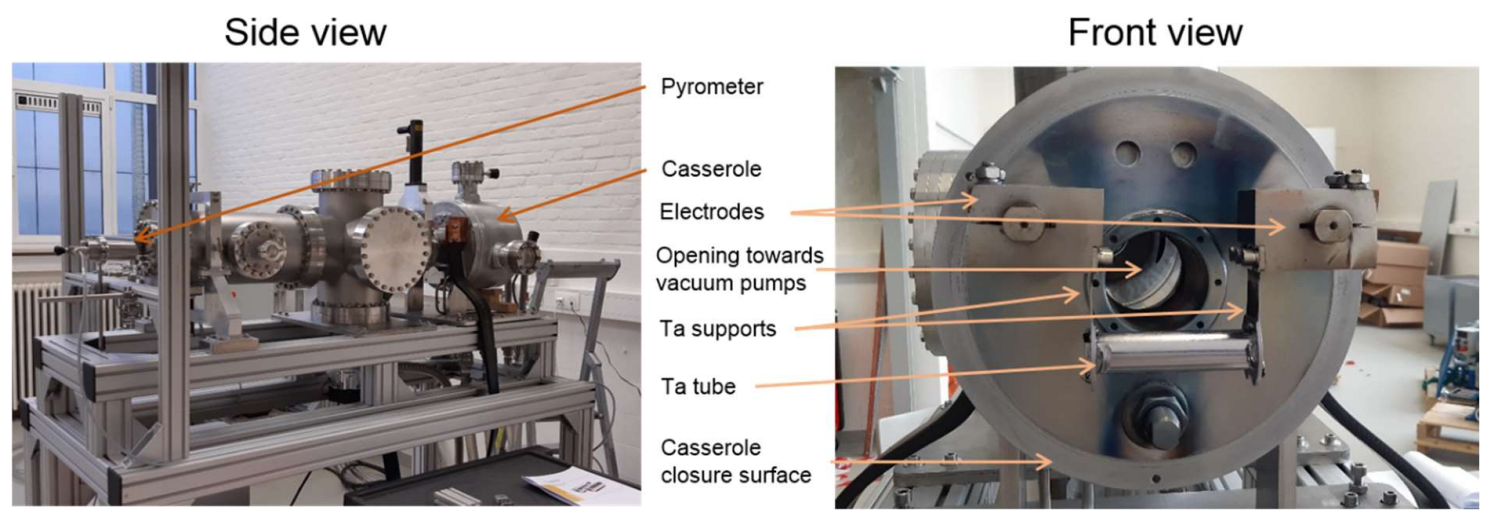

Fig. S6. The thermal test bench and its components.

The setup, shown in Fig. S6 with its most relevant components, comprises a resistively heated tube made of tantalum (Ta). The Ta tube resembles the container of an ISOL target and is also shown in Figs. S7a, S7c and S7e. The tube is hanging from two Ta legs connected directly to the electrical current source (made of $\mathrm{Cu}$ ) heating the tube. These parts are cased inside a pseudo-cylindrical volume enclosed by an Al vessel, which is actively cooled by means of an inner water flow. The purpose of the Al vessel is to absorb the heat radiated from the Ta tube. This space communicates with a larger cavity, which is connected to a turbo pump providing 
the vacuum level required for operation. A number of glass windows are present, allowing the inspection of the inside of the test bench, as well as the installation of a pyrometer for the direct measure of the heating tube temperature.
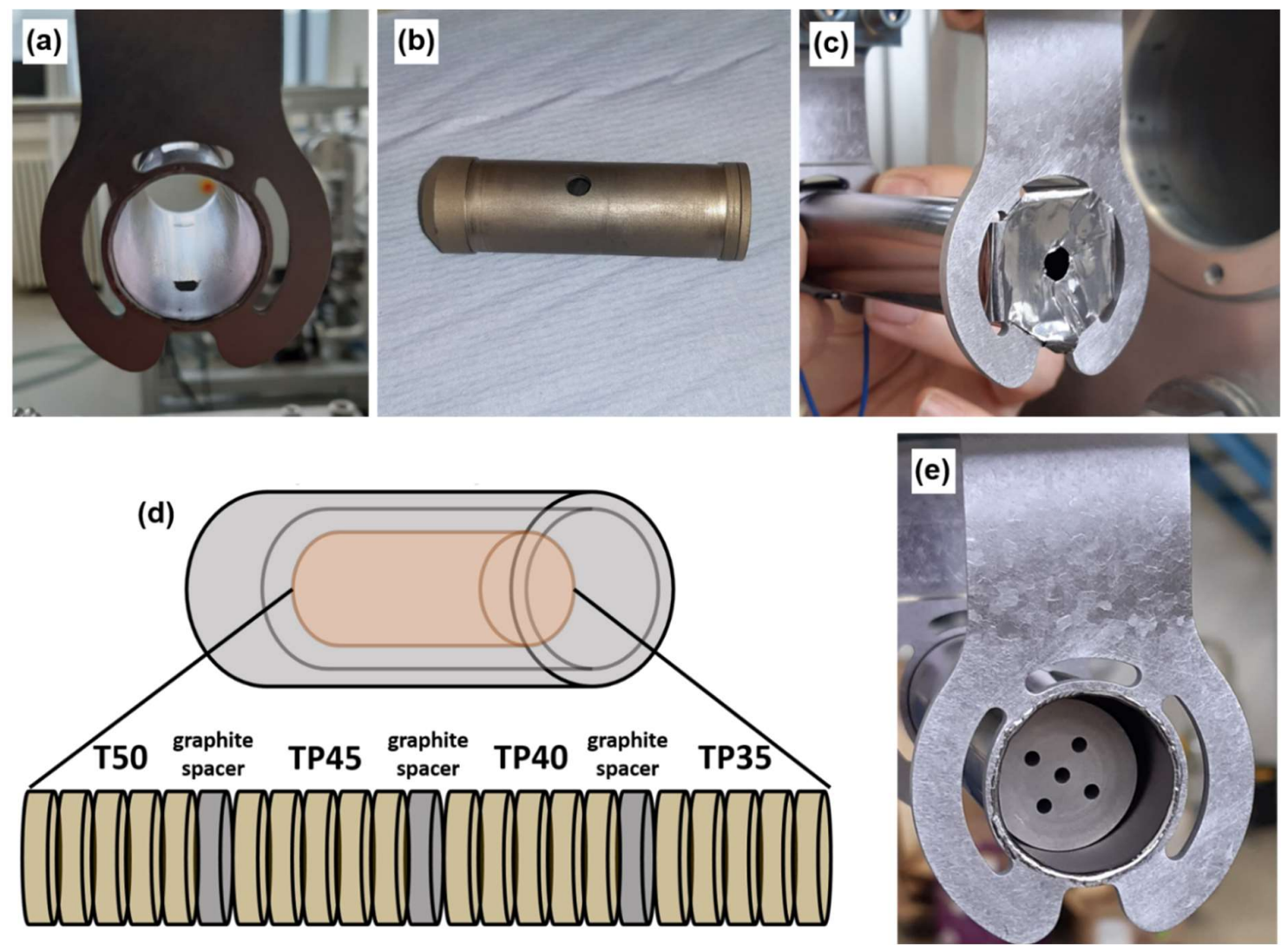

Fig. S7. (a) Empty Ta tube after pre-treatment showing the passivated TaC contact. (b) Graphite insert. (c) Ta foil used as heat shield. (d) Sample line-up inside the graphite insert. (e) Close-up of the loaded Ta tube and its supports, showing grain growth in the Ta.

The target material discs were loaded into a graphite insert (POCO, reactor grade high purity graphite, France), which is then directly inserted in the Ta tube. The design of the graphite insert (Fig. S7b) was inspired by the design of inserts used at CERN for material treatments at $\mathrm{T} \geq 2000^{\circ} \mathrm{C}$. The graphite crucible aimed at protecting the samples in a reducing atmosphere and at shielding as much as possible the thermal test bench from the samples themselves. The porous $\mathrm{TaC}_{\mathrm{x}}$ discs were horizontally stacked and loaded into a graphite cell specifically designed to fit in the heating tube cylindrical cell. The samples were arranged as shown in Fig. S7d, with graphite discs acting as spacers to separate the different grades. Moreover, all discs were spaced from one another by graphite foil to avoid sticking to each other during annealing. In order to guarantee that the graphite insert and the spacing discs were outgassed and free from impurities, the first heat treatment was conducted at $\sim 2000^{\circ} \mathrm{C}$ for $4 \mathrm{~h}$ with the setup kept only with the graphite parts without samples. The power supplies of the target container were brought up to $1050 \mathrm{~A}$ and the target container temperature in the hottest spot was $2117^{\circ} \mathrm{C}$. However, the graphite temperature at its coldest spot (sides of insert) was only $1576^{\circ} \mathrm{C}$. This is due to the sides of the container not being shielded and the high emissivity of graphite. In 
order to increase the temperature uniformity and increase the overall temperature in the graphite, based on ISOLDE experience, three spaced Ta foils were added to each side of the container. On the right shields, a hole was made to measure the temperature of the graphite insert with the pyrometer, as shown in Fig. S7c. With this configuration, the target container reached a maximum temperature of $2264^{\circ} \mathrm{C}$, while the graphite coldest point reached $1970^{\circ} \mathrm{C}$ also with $1050 \mathrm{~A}$ in the container power supplies.

During annealing, the insert and Ta container reacted together in two locations, forming $\mathrm{TaC}$ at the contact point, as seen in Fig. S7a. After heating at the annealing temperature, the Ta body composing the supports showed signs of grain grown, as shown in Fig. S7e.

\subsection{Temperature determination}

During annealing of the porous $\mathrm{TaC}_{\mathrm{x}}$ ceramics, the only method to determine the annealing temperature was a pyrometer pointed to the outer surface of the Ta tube (unlike the heating test runs). An inhomogeneous temperature distribution was expected in the heated system, due to several factors: presence of different materials and components (Ta tube, graphite insert, samples), each with its own heat conduction, high radiative heat at these high annealing temperatures, and lack of thermal insulation. It was, therefore, deemed appropriate to study how the temperature varied across the Ta body. As a first estimate of the variation of the direct pyrometer temperature reading, the point where it was directed was swept across a line of 1.8 $\mathrm{cm}$, performing multiple readings, as shown in Fig. S8a. This showed that along this line, the temperature varied by roughly $10^{\circ} \mathrm{C}$. In order to estimate the temperature distribution across the central axis of the graphite insert, where the samples were located, a temperature calculation was performed by means of the multiphysics simulation code ANSYS. In order to carry out this calculation, the emissivity, $\sigma$, and thermal conductivity, $\lambda$, of the materials were taken into account.
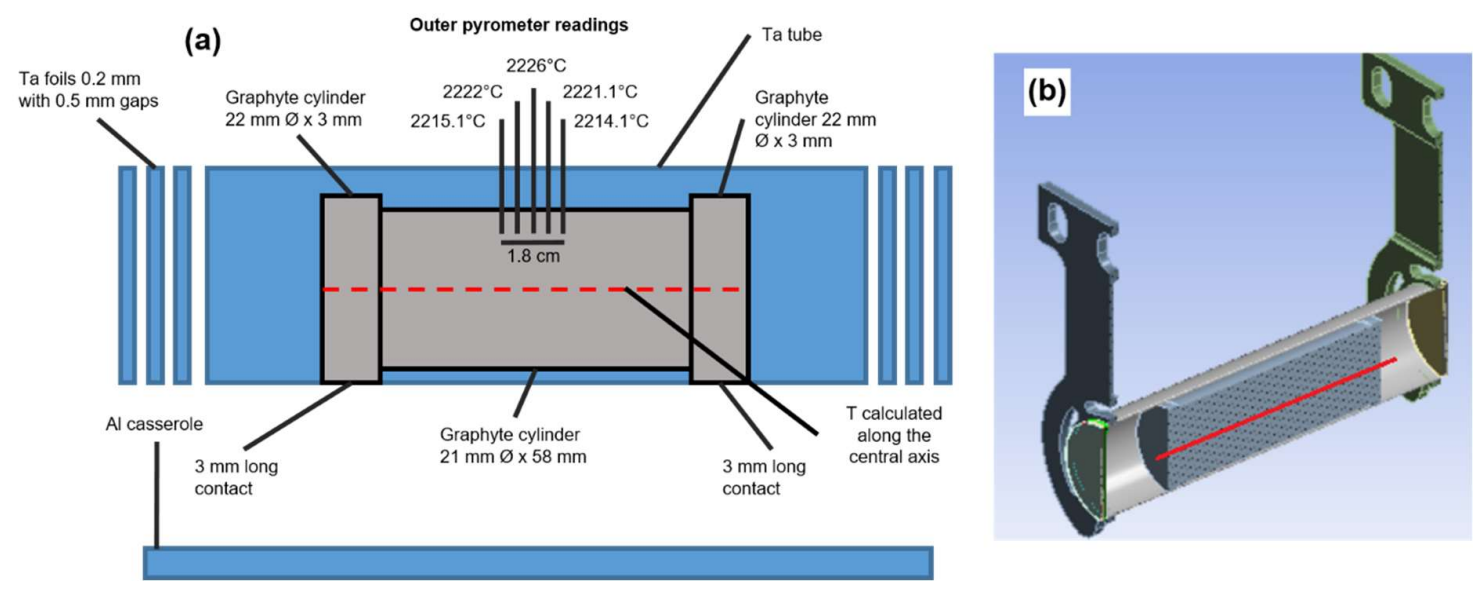

Fig. S8. (a) Schematic of the Ta tube containing the graphite insert and pyrometer used to measure the temperature on top of it. (b) Geometry as implemented in ANSYS.

The Ta tube surrounding the cell and the Ta heat shields were considered in two limiting scenarios with $\sigma_{T a}=0.2$ and 0.3 . The graphite, the exact thermal conductivity of which was not provided by the supplier, was modelled in two limiting cases: $\lambda_{\text {graphite }}=24 \mathrm{~W} / \mathrm{m} \cdot \mathrm{K}$ and $\lambda_{\text {graphite }}=$ $470 \mathrm{~W} / \mathrm{m} \cdot \mathrm{K}$, both with an emissivity $\sigma_{\text {graphite }}=0.9$. The inside of the insert was completely filled 
with graphite, in order to simulate a simplified but realistic situation where the target material samples are in equilibrium with the graphite insert. The boundary condition was imposed as external temperature of the Ta tube and measured directly with the pyrometer: $T_{\text {ext }}=2275^{\circ} \mathrm{C}$, when the current was $1050 \mathrm{~A}$, and $\mathrm{T}_{\mathrm{ext}}=2224^{\circ} \mathrm{C}$, when the setup was operated with a reduced current of $1000 \mathrm{~A}$, due to concerns regarding the overheating of the power supply. The outer temperature profile was considered constant along the tube length. These assumptions reduced the computation time, easing the comparison of eight separate scenarios. The temperature of the external vessel and its components was set to a constant temperature of $20^{\circ} \mathrm{C}$, with an airflow along the outer surface of the vessel of $22^{\circ} \mathrm{C}$. The schematic of the system is shown in Fig. S8a, and the geometry modelled in ANSYS is shown in Fig. S8b.

The purpose of the simulation was to calculate the equilibrium temperature distribution within the system. In Fig. S9, the temperature distribution across a central plane in the graphite holder is shown for all of the investigated cases. The temperatures gradients across the length of the graphite insert are more pronounced in the scenarios with lower graphite thermal conductivity. This result is due to the fact that the heat transfer from the insert to the Ta tube relies only minimally on direct contact, in consequence of the intentional shaping of the insert with two small steps that generate two small contact lines of $3 \mathrm{~mm}$ as the insert sits on the bottom of the tube. This create the conditions for an efficient temperature homogenization only when the thermal conductivity is high. Those contact points appear hotter in all cases. Another parameter that affects the simulation results is the Ta emissivity. In cases where the emissivity is higher, the higher amount of heat reflected back on the graphite insert causes the temperature to be slightly higher. While this does not accentuate the lengthwise gradient, since the insert is completely surrounded by Ta, the bottom of the insert, which is closer to the Ta inner wall, is slightly hotter than the top.

The final purpose of the study was to determine the upper and lower bounds of the actual temperature of the target material samples. From the full, lengthwise temperature profile for all examined cases shown in Fig. S10, it can be seen that the variation in emissivity causes a temperature difference of less than $10^{\circ} \mathrm{C}$ in all cases. The $\lambda_{\text {graphite }}=470 \mathrm{~W} / \mathrm{m} \cdot \mathrm{K}$ case shows almost no T gradient, while in the $\lambda_{\text {graphite }}=27 \mathrm{~W} / \mathrm{m} \cdot \mathrm{K}$ case, the differences between maximum and minimum temperatures are at most $20^{\circ} \mathrm{C}$ in the relevant section, i.e., the section where the samples were located within the insert (between $1 \mathrm{~cm}$ and $6 \mathrm{~cm}$ ). From these indications, it can be concluded that the average sample temperature when the setup was operated at $1050 \mathrm{~A}$ was $(2254 \pm 20)^{\circ} \mathrm{C}$, while the average sample temperature when the current was limited to $1000 \mathrm{~A}$ (in most of the conducted heat treatments) was $(2206 \pm 20)^{\circ} \mathrm{C}$. 


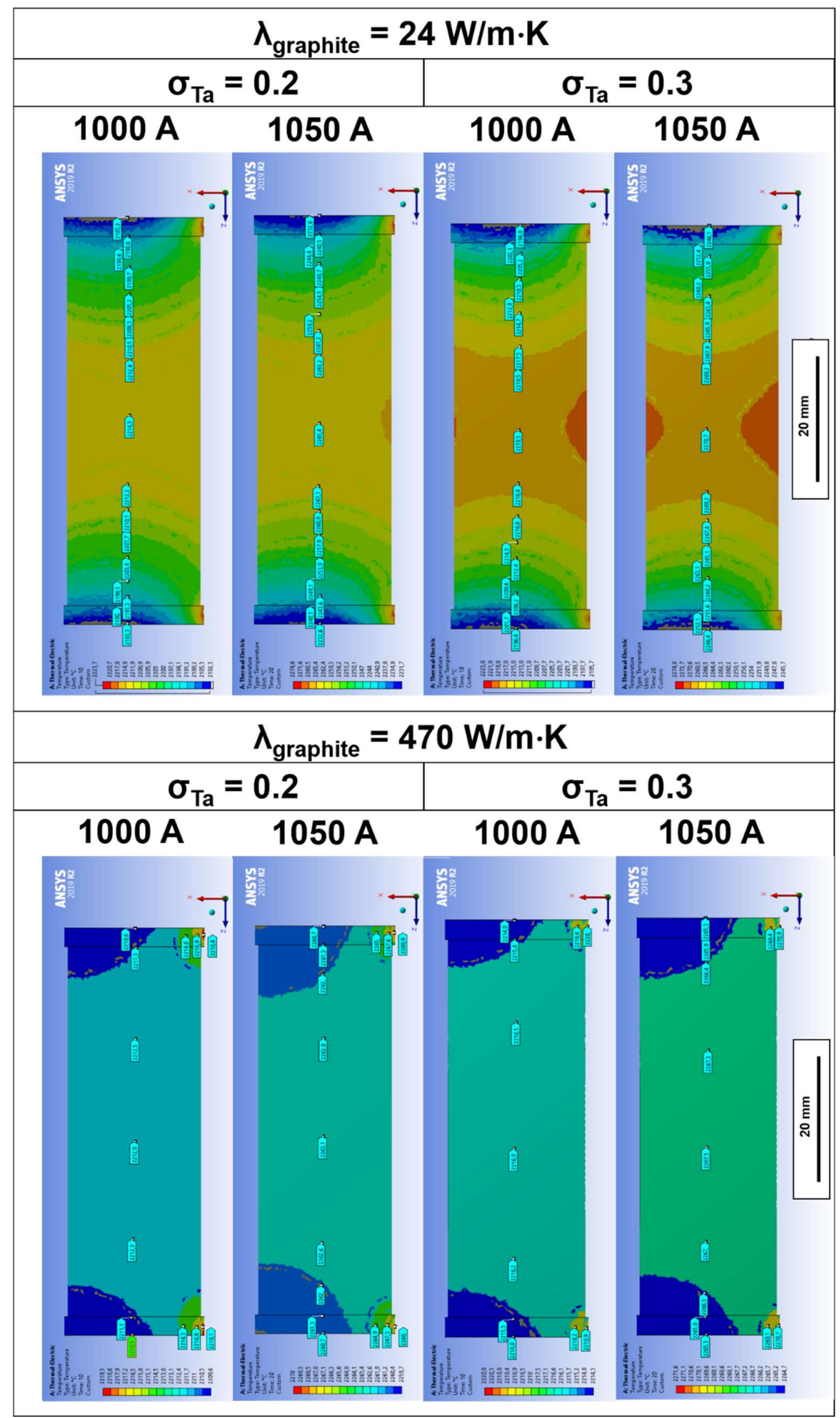

Fig. S9. Temperature distribution across central section planes of the graphite holder calculated with ANSYS in different limiting cases. The operation at $1000 \mathrm{~A}$ corresponds to a measured temperature of $2224^{\circ} \mathrm{C}$ on the external surface of the Ta tube, while the operation at $1050 \mathrm{~A}$ corresponds to $2275^{\circ} \mathrm{C}$. 


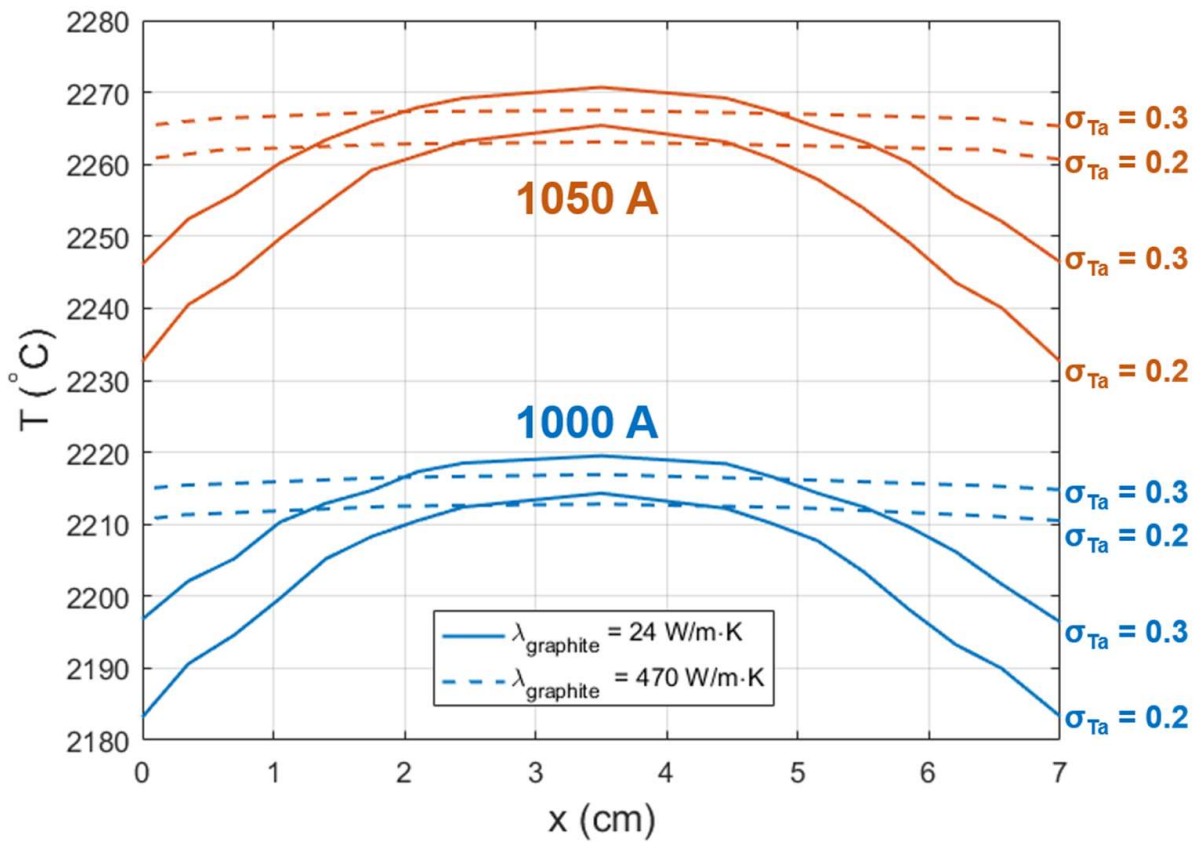

Fig. S10. Temperature profile across the central axis, as calculated with ANSYS in different limiting cases. 